\title{
O cotidiano ancestral e as representações sexuais rupestres no Parque Nacional Serra da Capivara - PNSC/PI - Brasil
}

\author{
The ancestral daily life and sexual rock art representations in the Park National Serra da
}

\author{
Capivara- PNSC/PI - Brazil
}

La vida diaria ancestral y las representaciones de arte rocal sexual en el Parque Nacional Serra da

Capivara - PNSC / PI - Brasil

\author{
Michel Justamand \\ ORCID: https://orcid.org/0000-0001-6944-5890 \\ Universidade Federal de São Paulo, Brasil \\ E-mail: micheljustamand@yahoo.com.br \\ Washington Ramos dos Santos Junior \\ ORCID: https://orcid.org/0000-0003-0198-485X \\ Universidade Estadual do Centro-Oeste, Brasil \\ E-mail: washingtonramos@usp.br \\ Gabriel Frechiani de Oliveira \\ ORCID: https://orcid.org/0000-0003-3528-2944 \\ Secretária de Educação do Estado do Piauí, Brasil \\ E-mail: gfrechiani@hotmail.com \\ Antoniel dos Santos Gomes Filho \\ ORCID: https://orcid.org/0000-0003-2230-4315 \\ Mestre Centro Universitário Vale do Salgado, Brasil \\ E-mail: antoniel.historiacomparada@gmail.com \\ Vitor José Rampaneli de Almeida \\ ORCID: https://orcid.org/0000-0001-8470-2672 \\ Universidade Federal do ABC, Brasil \\ E-mail: vitor.almeida@ufabc.edu.br \\ Matteus Freitas de Oliveira \\ ORCID: https://orcid.org/0000-0002-4103-187X \\ Instituto Federal de Alagoas, Brasil \\ E-mail: matteus.oliveira@ifal.edu.br \\ Vanessa Belarmino da Silva \\ ORCID: https://orcid.org/0000-0002-1973-6830 \\ Universidade Federal Vale do São Francisco, Brasil \\ E-mail: vanessabela18@ hotmail.com \\ Losa Vilella \\ ORCID: https://orcid.org/0000-0001-9286-7186 \\ Universidade Federal do Rio de Janeiro, Brasil \\ E-mail: lbreu1998@gmail.com
}

\begin{abstract}
Resumo
O presente trabalho tem por finalidade demonstrar que, nas temáticas da sociabilidade e da sexualidade rupestres, cenas que são encontradas em diversos sítios arqueológicos ao redor do mundo também ocorrem nos sítios existentes no Parque Nacional Serra da Capivara (PNSC), no Piauí, Brasil. Selecionamos, desse modo, cenas de nascimentos; de antropomorfos sem e com diferenciação sexual, por meio da presença de bastão itifálico e de signos que se referem à vagina; de relações sexuais atualmente designadas como heterossexuais e homossexuais, incluindo nestas a possibilidade de um registro de homossexualidade feminina; de bestialidade; e, por fim, de sociabilidades mediadas ou pela violência ou pelo espírito coletivo. Esse trabalho se insere em novas abordagens teórico-metodológicas de estudos culturais, como a Arqueologia de Gênero e Queer, que subvertem os pressupostos tradicionais da ciência arqueológica, além de tensionarem a forma como está tem contribuído para a manutenção do binarismo e dimorfismo de gêneros e sexualidades. Nesse sentido, compreender o funcionamento e a estrutura das práticas sexuais e sociais nas sociedades ancestrais contribui para compreender essas relações contemporaneamente. A metodologia do trabalho consiste nas pesquisas bibliográfica e de campo, a fim de localizar no PNSC cenas rupestres relacionadas às temáticas pesquisadas. Palavras-chave: Arte rupestre; Sociabilidade; Sexualidade; Homoerotismo; Parque Nacional Serra da Capivara.
\end{abstract}




\begin{abstract}
The present work aims to demonstrate that, in the themes of prehistoric sociability and sexuality, scenes that are found in several archaeological sites around the world also occur in the existing sites in the Serra da Capivara National Park (PNSC), in Piauí, Brazil. In this way, we selected birth scenes; anthropomorphs without and with sexual differentiation, through the presence of an itiphallic stick and signs that refer to the vagina; of sexual relations currently designated as heterosexual and homosexual, including the possibility of a record of female homosexuality; bestiality; and, finally, sociability mediated either by violence or by the collective spirit. This work is part of new theoretical and methodological approaches to cultural studies, such as Gender and Queer Archeology, which subvert the traditional assumptions of archaeological science, in a manner of tensing the way in which it has contributed to the maintenance of gender binarism and dimorphic sexualities. In this sense, understanding the functioning and structure of sexual and social practices in ancestral societies contributes to comprehending these relationships nowadays. The methodology of this work consists of bibliographic and field research, in order to locate in the PNSC rock scenes related to the researched themes.
\end{abstract}

Keywords: Rock art; Sociability; Sexuality; Homoeroticism; The National Park Serra da Capivara.

\title{
Resumen
}

El presente trabajo tiene como objetivo demostrar que, en los temas de sociabilidad y sexualidad de las rocas, las escenas que se encuentran en varios sitios arqueológicos alrededor del mundo también ocurren en sitios existentes en el Parque Nacional Serra da Capivara (PNSC), en Piauí, Brasil. De esta forma seleccionamos escenas de nacimientos; de antropomorfos sin y con diferenciación sexual, mediante la presencia de un palo itifálico y signos que se refieren a la vagina; de las relaciones sexuales actualmente designadas como heterosexuales y homosexuales, incluyendo en estas la posibilidad de un registro de homosexualidad femenina; de bestialidad; $y$, finalmente, de las sociabilidades mediadas por la violencia o por el espíritu colectivo. Este trabajo es parte de nuevos enfoques teórico-metodológicos de los estudios culturales, como la Arqueología del Género y Queer, que subvierten los supuestos tradicionales de la ciencia arqueológica, además de enfatizar la forma en que ha contribuido al mantenimiento del binarismo y el género. dimorfismo y sexualidades. En este sentido, comprender el funcionamiento y la estructura de las prácticas sexuales y sociales en las sociedades ancestrales contribuye a comprender estas relaciones de manera contemporánea. La metodología de trabajo consiste en la investigación bibliográfica y de campo, con el fin de ubicar en el PNSC escenas rocosas relacionadas con los temas investigados.

Palabras clave: Arte rupestre; Sociabilidad; Sexualidad; Homoerotismo; Parque Nacional Serra da Capivara.

\section{Introdução}

No âmbito das investigações rupestres, as discussões acerca das vivências pré-históricas têm se tornado mais frequentes, sobretudo através de recentes questionamentos provocados a partir da descoberta e/ou consideração de cenas rupestres sobre possíveis diversidades de gêneros e sexualidades, temáticas complexas que povoam reflexões, talvez, contemporâneas. Assim, o ato de olhar para o passado está sempre impregnado pelo momento em que se efetua essa ação, e isso ocorre em todas as ciências e não apenas na Arqueologia mesmo quando se tenta escapar, teórico e metodologicamente dos riscos de realizar análises anacrônicas. Este exercício interpretativo nos permite compreender com maior profundidade as dinâmicas sociais dos grupos humanos que ocuparam a atual região Nordeste do Brasil, onde hoje está situado o Parque Nacional Serra da Capivara (PNSC).

Esta unidade de conservação de proteção integral localiza-se nos municípios de São Raimundo Nonato, João Costa, Coronel José Dias e Brejo do Piauí, na região Sudoeste do Piauí, compreendendo uma área de aproximadamente 130.000 hectares e um perímetro de $214 \mathrm{~km}^{2}$, e foi criado em 1979. A Figura 1 mostra a localização do PNSC. Anos depois, em 1986, a fim de contribuir para a preservação do patrimônio e para a condução de pesquisas científicas e ações socioambientais na área do PNSC e em seu entorno, foi criada a Fundação Museu do Homem Americano (FUMDHAM), com o apoio de pesquisadores brasileiros e franceses, e dirigida pela Dra. Niède Guidon. Em 1991, o PNSC foi considerado Patrimônio Cultural da Humanidade pela Organização das Nações Unidas para a Educação, a Ciência e a Cultura (UNESCO, em inglês), e, em 1993, Patrimônio Nacional pelo Instituto do Patrimônio Histórico e Artístico Nacional (IPHAN). 
Figura 1: Localização do Parque Nacional Serra da Capivara.

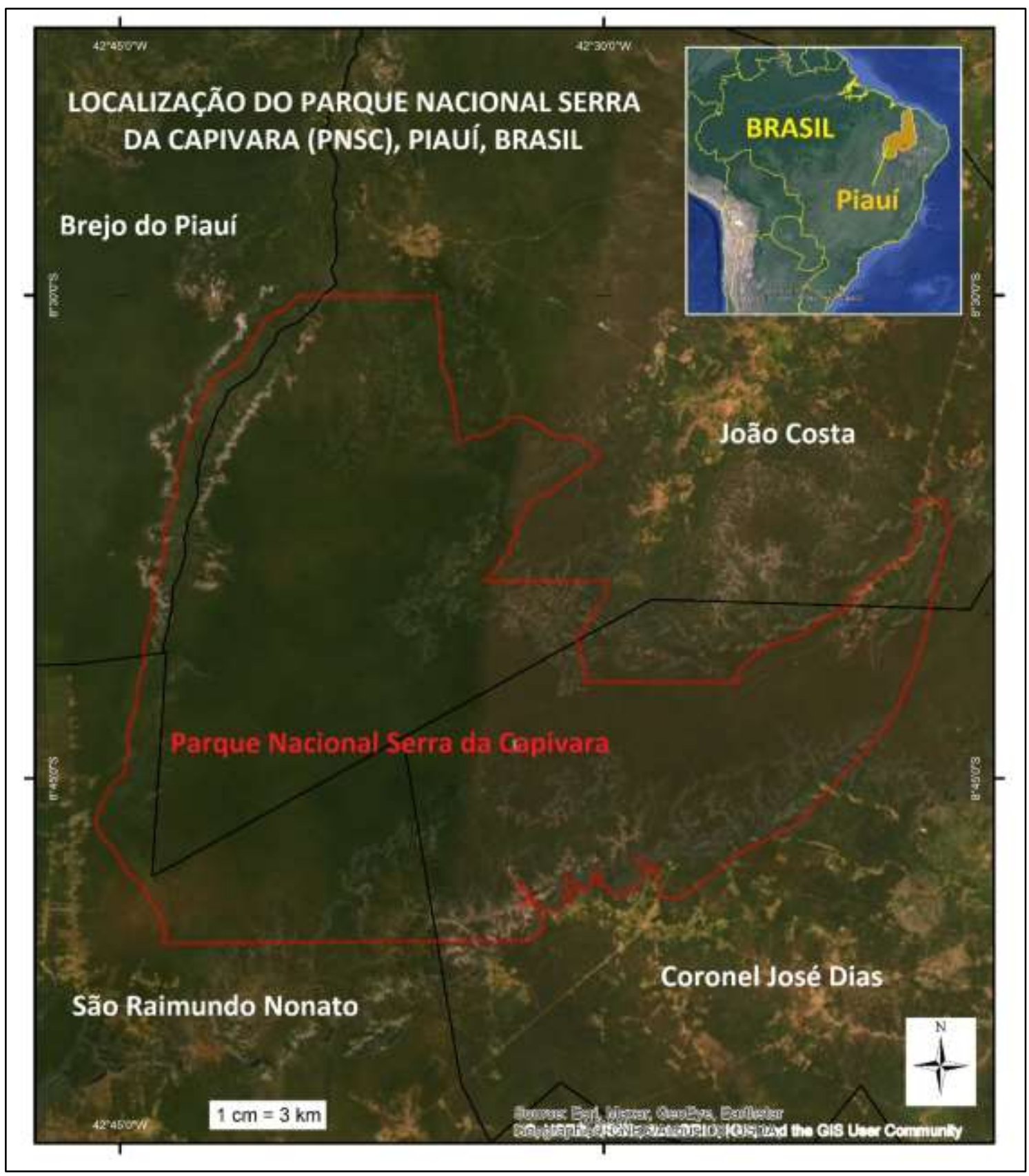

Fonte: Santos Junior (2021).

Entre os dias 25 de janeiro de 2018 e 02 de fevereiro de 2018, empreendemos atividades científicas no parque, oportunidade em que observamos representações rupestres de caças, confrontos, ritos religiosos e diversas formas de convívio social, bem como relações sexuais em toda a sua diversidade, incluindo cenas entre pessoas de sexos e idades - supostamente diferentes, de mesmo sexo e até mesmo com animais, possibilitando a ampliação da reflexão sobre os gêneros e as sexualidades realizadas por Foucault (1987) ao pensar nas disciplinas e instituições normatizadoras no qual engendraram a atuação das tecnologias sociais para a produção de corpos, gêneros e sexualidades numa perspectiva binarista na era Vitoriana no século XVIII. Investigamos cinquenta e um sítios arqueológicos com pinturas rupestres. Considerando-se a vasta bibliografia sobre a região, os sítios foram previamente selecionados a fim de obter uma experiência interpretativa. Nesse sentido, os trabalhos de campo ambicionavam reunir o maior número possível de cenas sexuais entre pessoas do mesmo sexo. Poucos são os trabalhos que analisam possíveis cenas de relações homossexuais na arqueologia brasileira, e muitos trabalhos reafirmam o binarismo de 
gênero. Para problematizar e ampliar possibilidades de análises arqueológicas desde 2017, Michel Justamand e Mário Filho ${ }^{1}$, condutor credenciado para atuar no parque, mantiveram contato permanente, na busca de figuras e cenas que pudessem contribuir para a discussão proposta.

Ademais de obrigatória, a orientação e a condução determinada pelo guia credenciado foram consideradas por nós essenciais frente às distâncias e dificuldades de locomoção dentro das áreas do parque, considerando as suas dimensões, acidentes geográficos e perigos iminentes, como animais selvagens, por exemplo. A delineação de rotas e planificação prévia das pesquisas de campo foram fundamentais para o presente estudo, visto que o tempo era exíguo e custos, consideráveis. Outra questão importante foi a possibilidade de que todos os envolvidos com a empreitada pudessem estar ali juntos, naquele mesmo período. Partimos para a investigação de campo e formamos uma equipe, aqui representados como autores deste texto.

\section{Metodologia}

Consideramos admirável que, na arte ancestral, as informações inscritas, em rochas, especialmente, tratavam de mostrar o que os grupos humanos consideravam substancial em suas vidas. As pinturas rupestres apresentam-se como potentes "textos", capazes de revelar nuances de um passado pouco materializado, além decontribuir para a compreensão de formas-objetos espaciais e subjetividades que dão sentido às representações e práticas sociais da contemporaneidade. Nessas artes, estavam contidas uma forma de reverência desses ancestrais aos poderes criativos da natureza, e Eisler (1996) sugere que faziam isso por meio das imagens sexuais e/ou de nascimentos, como vemos na Figura 2.

Figura 2: Registro rupestre de nascimento no Jebel Yagur, no Marrocos.

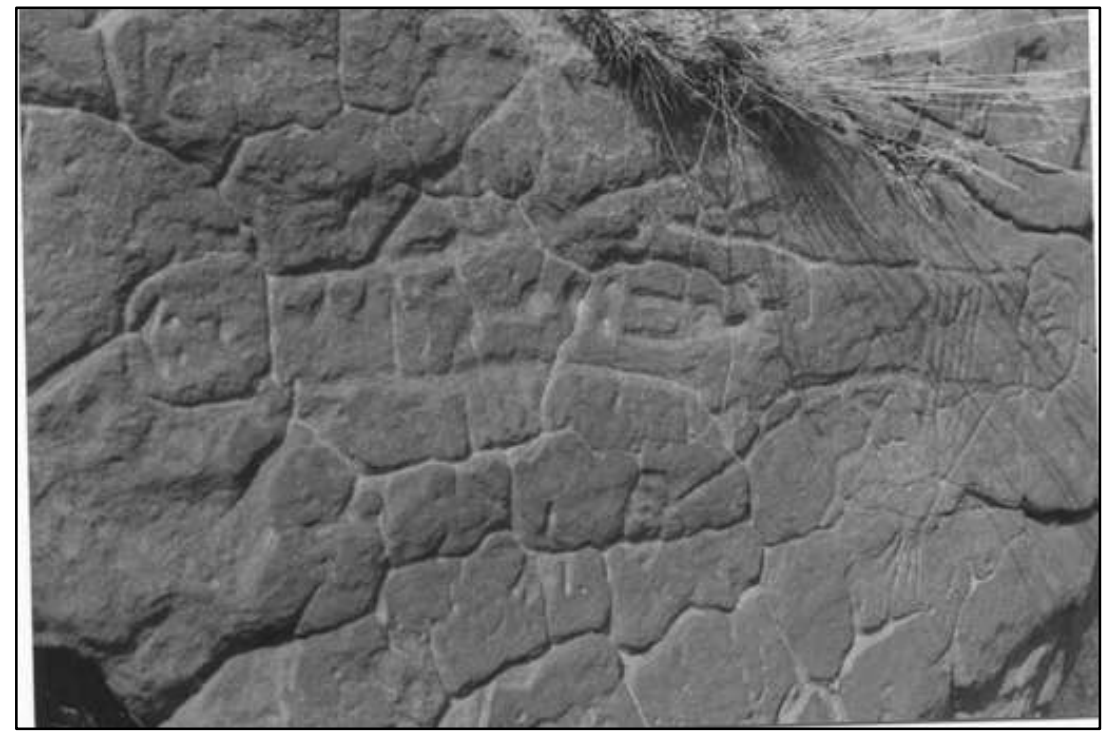

Fonte: Simoneau (1977) apud Searight-Martinet, (2016).

Um caso curioso que cabe destacar está presente em Mithen (1996, p. 195), em que há a menção a um propulsor feito de chifre encontrado em Mas d'Azil, França, na década de 1940 (Garrod, 1955). Esse artefato traz uma cena que é interpretada ou como o nascimento de um íbex ou como uma enorme matéria fecal. Isso remete-nos à sexualidade infantil da teoria cloacal que desconhece ou nega o órgão sexual feminino.

${ }^{1}$ Agradecemos o empenho e atenção de Mario Filho guia turístico da Associação de Guias da Capivara, bem como a todos os funcionários da FUMDHAM que possibilitaram o caminhar de nossa expedição. 
Por isso, talvez, as figuras com conotações voltadas para as sexualidades tenham um papel importante, uma vez que este aspecto da vida humana é fundamental para a sobrevivência da espécie, e também como mediadora das relações sociais e individuais como apontam Freud (2012), Fuks, Basualdo e Braunstein (2013) e Gontijo e Schaan (2017). A temática das sexualidades é muito recorrente em inúmeras formas de expressão artísticas e culturais da humanidade, desde tempos imemoriais. Como Eisler (1996), Stearns (2010) destaca que a arte primitiva tinha forte conteúdo sexual. Concordando com os argumentos dos autores, acreditamos que as sexualidades do passado podem contribuir para entendermos e explicarmos as complexidades dos comportamentos sexuais no presente $\mathrm{e}$, por isso, chamamos a atenção para a quantidade de cenas voltadas às possíveis práticas sexuais encontradas no PNSC e que podem tensionar as temporalidades e as compreensões que estão estabelecidas nas ciências sociais e humanas sobre o entendimento de corpos, gêneros e sexualidades (Foucault, 1987; Butler, 2003), já que o sexo entre as pessoas de mesmo sexo e animais já eram práticas entre nossos ancestrais.

Nesse sentido, as pinturas rupestres, que falam dos outros, os quais a Arqueologia pretende conhecer, possuem a capacidade de integrar materialidades/imaterialidades, marcas/ideias, necessidades e vontades em uma só realidade complexa, enquanto fonte de múltiplas análises e interpretações (Fagundes, Bandeira \& Greco, 2018). Sem dúvida, a sexualidade é algo presente dentro do universo simbólico dos grupos humanos pré-coloniais que viveram nessa região (Justamand \& Funari, 2017), o que pode ser facilmente comprovado por meio do grande número de recorrências observadas. As diversas cenas encontradas no PNSC, sejam de ordem sexual ou não, apontam para a importância do corpo humano, suas representatividades e práticas sociais que são diversas e encontram-se espalhadas no mundo, se constituindo em vestígios que nos desafiam a refletir sobre a concepção arqueológica de corpo, enquanto significado e significante, para além da tradicional arqueologia das materialidades.

Justamand (2011) propõe que a cultura visual é expressamente corporal, por vezes sexualmente marcada. Buco et al. (2020) afirmam que esse ponto é importante para se pensar como nossos ancestrais se relacionavam socialmente. Como nos lembra o autor, em menção a Le Breton (2003), esse corpo ancestral é construído de certo modo, e nos estudos sobre arte rupestre podemos apontar que este é reconstruído nas interpretações contemporâneas. Assim, compreendemos que há uma questão latente, que é como interpretar essas recorrências arqueológicas. Vlachopoulos (2020) propugna que a "Arqueologia é um exercício de Antropologia Social sobre as sociedades do passado". A analogia direta não é uma resposta unilateral, já que é necessário observar as recorrências no registro rupestre, os vestígios arqueológicos diretos encontrados no local e tentar construir uma ponte entre presente e o passado, para acessar a ambos.

É necessário que se diferencie, portanto, entre um registro antropomorfo e outras formas de vida e demais signos representados, por meio da representação constituída de forma icônica. Assim, ainda que haja interpretações, é inegável o reconhecimento de ícones, o que, sem isso, tornaria impossível qualquer análise de registro rupestre. Grafismos e símbolos dificilmente gerarão algum tipo de consenso, uma vez que o passado é uma alteridade. Para reconhecer um antropomorfo, os elementos que devem ser buscados no desenho são cabeça, eixo da coluna vertebral, membros superiores e inferiores e uso de equipamentos manuais ou adereços. Além disso, o desafio de analisar uma obra de arte não ocidental, como vemos na Figura 3 a partir de uma perspectiva ocidental, pode acarretar uma série de problemas de intepretação, uma vez as percepções são subjetivas e estão associadas ao contexto do observador, gerando uma série de possibilidades (Guidon, 1984). 
Figura 3: Cena digitalizada de antropomorfos caçadores com base em escaneamento e fotografia de registros da caverna de Valltorta, Espanha.

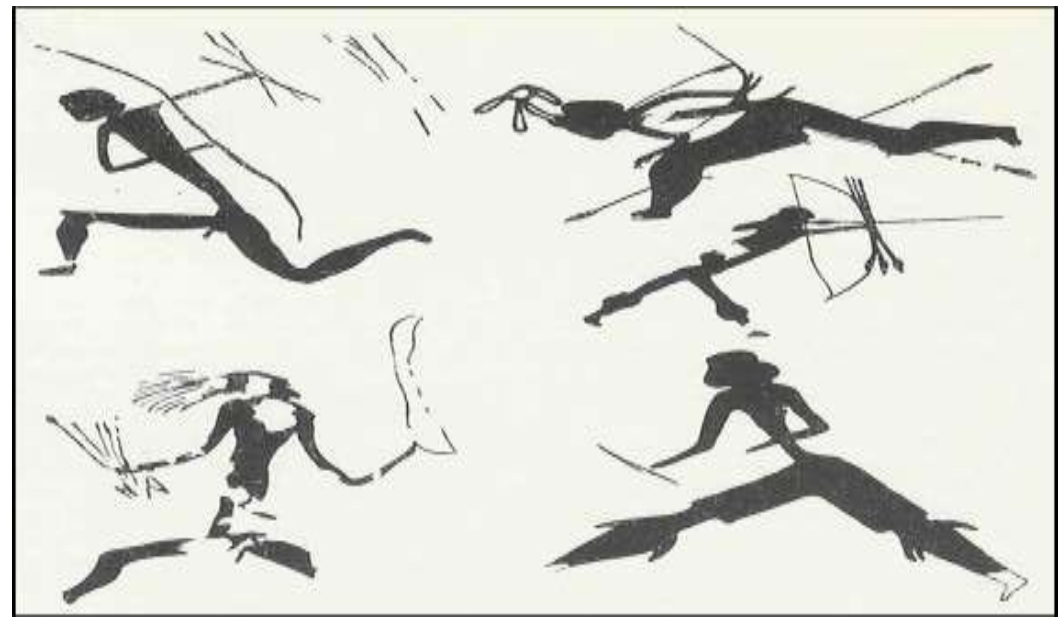

Fonte: Behn e Wölfel, (1972, p. 26).

Assim, o exercício interpretativo estará sempre vinculado à possibilidade de crítica e à negação de determinado viés, segundo a Weltanschauung, a cosmovisão, de cada pesquisador, isso implica inferir que os silêncios sobre determinados cenas e gravuras, presentes em muitos tratados clássicos em áreas de ocorrência de pinturas de sexo entre pessoas do mesmo gênero, decorrem de posturas politicas a favor a normatização da história, assim a Arqueologia serviu para o aprisionamento dos corpos, dos gêneros e das sexualidades. Timothy Taylor (1997) aponta que as artes rupestres contribuem para ampliar a compreensão, o reconhecimento e a discussão de como eram as relações entre os humanos pré-históricos. O filósofo Robin George Collingwood (1986) explicita a construção dessa conjectura do passado e a tentativa de leitura dele. O autor (ibid., p. 25) afirma que

“[s]e dois historiadores dessem cada um a própria resposta à questão 'Que tipos de eventos ocorrem, ou podem ou poderiam ocorrer na história', as respostas seriam extremamente diferentes se um deles habitualmente pensar sobre um evento como algo que leva uma hora e o outro como algo que leva dez anos; e um terceiro, que concebesse um evento como levando até 1000 anos, daria mais uma vez uma resposta diferente (tradução nossa).

Hodder (1994) afirma que o substrato dos arqueólogos na leitura de um passado é a cultura material, tendo seus sinais como as artes rupestres uma parte da cultura. A partir da análise desta, em forma de vestígios e fatos arqueológicos, é possível compreender o modo de vida dos grupos humanos do passado e do presente. Para Layton (2001a), a dificuldade de análise de artefatos pré-históricos reside na conciliação entre a subjetividade do pesquisador e a materialidade arqueológica, devendo o arqueólogo compreender os significados percebidos em razão do contexto arqueológico. O desafio de resgatar sentidos, significados e significações reside na tentativa de reconstrução e compreensão do repertório cultural que envolve uma Figura ou cena rupestre, no qual ao longo do tempo pode ter sido fonte de informação para grupos migratórios ou ainda refeito e reinterpretados por outros grupos que permaneceram mais tempo no local. A partir de Le Goff (1990) acessamos as artes rupestres para além da concepção de monumento, compreendendo-as como documento revelador do mundo, uma herança, uma representação e uma possibilidade de registro da vida cotidiana e do espaço e suas possibilidades.

Com efeito, há a necessidade de se recorrer à Semiótica, a fim de obter informações acerca do criador, os grupos humanos, e de sua obra, a cultura material e as interpretações possíveis dos dados arqueológicos. Estas associam-se à Antropologia pré-histórica, que permite a investigação da estrutura de determinado núcleo humano. A Arqueologia serviria como uma ponte entre o presente e o passado (Shanks \& Tilley, 1988, p. 23-24).

Esta narrativa arqueológica do passado pode ser alterada a partir de dois fatores, a primeira está ligada a novas evidências arqueológicas descobertas e a segunda se refere as modificações na estrutura política da sociedade e da própria disciplina (UCKO, 
2005). Já Boas (2004), cita a importância dos processos adaptativos dos grupos humanos para solucionar problemas do seu cotidiano, visando melhor integração ao meio ambiente. Esse autor afirma que as obras de arte aborígenes possuem alto grau de habilidade técnica, nas quais elementos como simetria e ritmo são os principais critérios de análise utilizados em sua realização. Assim poderiam ter sido as contribuições das artes rupestres para os nossos ancestrais e suas relações com o seu entorno.

Nesse sentido, em vez de se pensar em tradições, sub-tradições e estilos como unidade cultural de apenas um determinado grupo, em abordagem monotética, propomos que é plausível, outrossim, pensar, como opções artísticas e estratégia de um grupo cultural, a alteração de dado estilo em um lugar, sem que necessariamente se trate de um novo grupo cultural, mas apenas uma escolha, relacionada ou não, a modificações ambientais e efeitos migratórios, filiando-nos a uma abordagem politética (Clarke, 1968; Helskog, 1995, pp. 258-9; Justamand, Oliveira \& Gomes Filho, 2020). Todavia, as representações de possíveis sexualidades pré-históricas são recorrentes em todo o planeta e não se encontram apenas no PNSC, à revelia de possíveis diferenças e alterações naturais e sociais, como diferentes registros rupestres nos mostram; ou seja, alguns temas estão presentes em praticamente todas as concentrações de arte rupestre ao redor do mundo. Há cenas de grupos humanos reunidos e de diversas manifestações da sexualidade, assim como cenas de caçadas, partos, ritos místicos, danças e de outras temáticas.

Parece-nos que era condição sine qua non da nossa espécie, desde milhares de anos atrás², publicar suas práticas sociais e sexuais, ao deixar marcadas as rochas para a eternidade. Assim, se em muitas cenas, como as de caça e de rituais não evidenciamos marcações de ordem sexual, em algumas pinturas as marcações sexuais ficam evidentes, como meio de comunicação destas relações, observando-se, portanto, possíveis posições sociais e sexuais que reverberam a organização desses grupos humanos. Devemos lembrar que há estatuetas, gravuras e pinturas rupestres que não demonstram com clareza o sexo, como na Figura 4. Por exemplo, segundo Helskog (1995) 70\% das figuras de Alta, sítio da Noruega ártica, não trazem identificação de sexo. Para Helskog (1995, p. 257.), o importante "era o que os espíritos faziam e não o sexo deles", pensando que as figuras poderiam ser interpretadas tanto como pessoas reais quanto espíritos. Para alguns autores, a indiferenciação sexual representa o que hoje nomearíamos como figuras andróginas (Adovasio, Soffer \& Page, 2009).

Figura 4: Excerto de cena digitalizada com base em escaneamento e fotografia de registros do sítio de Hjemmeluft, Alta, Noruega em que não há diferenciação sexual.



Fonte: Tansem e Johansen, (2008, p. 70).

\footnotetext{
${ }^{2}$ Recentemente, foi descoberta a mais antiga pintura rupestre do mundo, com datação de pelo menos 45 mil anos. $C f$. Gopalakrishnan, 2021.
} 
Lins (2012) aponta que entre os grupos de caçadores e coletores, configurava-se a prática da exogamia, em que os membros copulavam com pessoas de fora do seu círculo de vivência imediato. Nesse sentido, ocorriam festas e encontros periódicos entre distintos grupos, o que reiterava a significância desses eventos para uma série de situações, especialmente as ampliações dos vínculos, não apenas sociais, mas também sexuais ilustradas na Figura 5.

Figura 5: Cena de um xamã entra em transe, com sangue escorrendo de seu nariz na província de Eastern Cape, na África do Sul.



Fonte: Clottes e Lewis-Williams, (1996, p.13).

Segundo Dubal (2017), encontram-se vestígios da temática heterossexual, no que tange a prática sexual, na Austrália, na Nova Caledônia e na Itália, e Mykhailova (2017) aponta para sua ocorrência na Rússia. A Figura 6 traz exemplos desse tipo de sexualidade. Há, ademais, ocorrências relacionadas à sexualidade em Chauvet, França (Fritz \& Tosello, 2015; Gray, 2010), e no sítio de Nawarla Gabarnmang, na Austrália (Gunn \& Lowish, 2017). A Preferência Homossexual Masculina (PHM) (ou MHP, em inglês) em ocorrências arqueológicas, ainda levanta polêmicas (Barthes, Crochet \& Raymond, 2015, pp. 4; 11). Especificamente sobre isso, podemos citar o trabalho de Barthes, Crochet e Raymond (2015), com atribuição de ocorrências homoeróticas na Noruega, na Espanha, na Suécia, no Peru e no Egito; de Epprecht (2013), com ocorrência no Zimbábue; e de Vlachopoulos e Matthaiou (2014, p. 386), com ocorrência de inscrição do século VI A.E.C na Grécia. O Quadro 1 em seguida exibe registros que são atribuídos à PHM.

Figura 6: Cena de relação heterossexual em Brady Creek, Austrália.

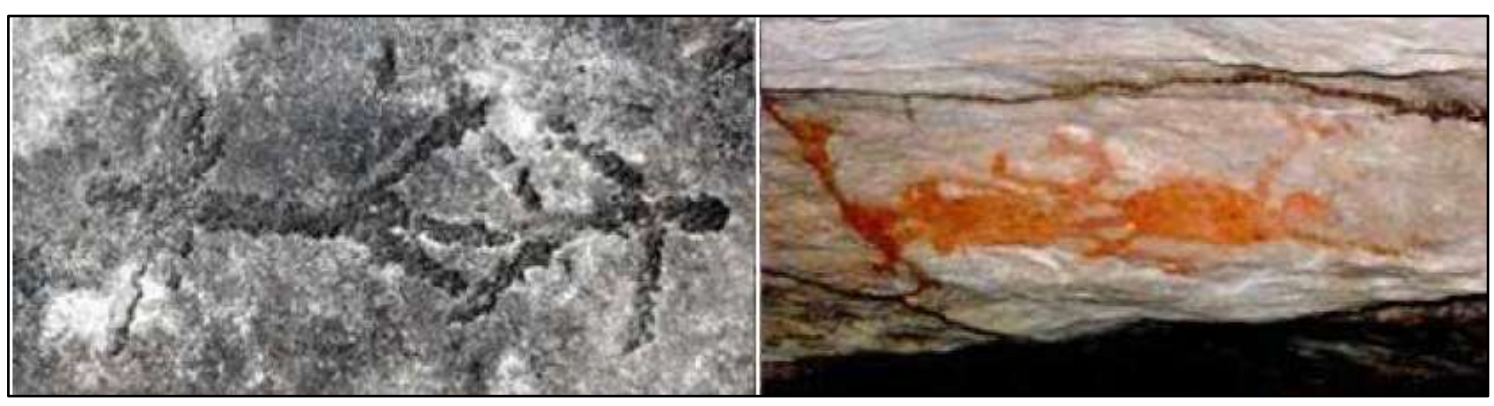

Fonte: Dubal, (2017). 
Quadro 1: Registros rupestres homoeróticos: à esquerda, no alto, em Tanum, Suécia; cena digitalizada de pintura rupestre no Zimbábue, no alto à direita; na parte de baixo, inscrição grega em que se lê "Nikasitimos esteve aqui cavalgando/tendo relação sexual com Timiona".

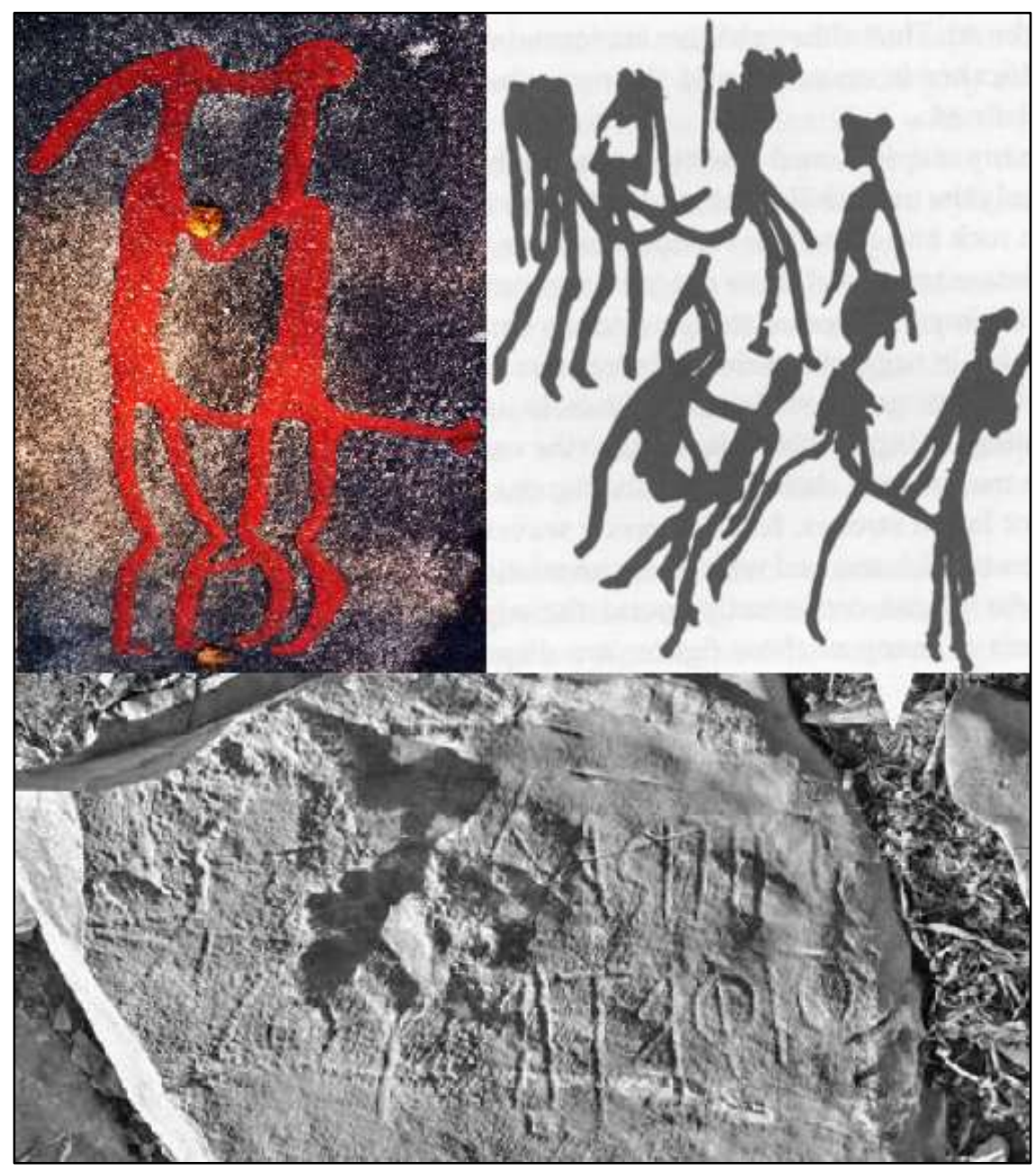

Fonte: The Arctic University of Norway, (2014, p. 41); Epprecht, (2013, p. 11); Vlachopoulos e Matthaiou, (2014, p. 386).

Baseados nos vestígios deixados por humanos pretéritos, percebe-se que os nossos parentes mais antigos realizavam práticas sexuais que poderiam ser consideradas, contemporaneamente, como comuns à maioria dos sujeitos. Contudo, uma manifestação encontrada globalmente nos registros rupestres (Goldhahn \& Fuglestvedt, 2012, p. 251; Sansoni \& Gavaldo, 2015) é a bestialidade, atualmente criminalizada em diversos países. Aggrawal (2011, p. 73) lembra que o termo bestialidade se refere "ao contato sexual entre um humano e um animal sem que o humano desenvolva qualquer tipo de laço emocional com o animal", de modo oportunista e isolado na falta de parceiro adequado; isso é diferente de zoofilia, está enquadrada como necessariamente patológica e classificada internacionalmente como doença.

Um dos entraves para o desenvolvimentos de análise na distinção entre zoofilia e bestialidade é que não há como afirmar, no contexto docomportamento da época, se a prática era patológica ou era concebida como prazer; e, em segundo lugar, porque não é possível acessar as subjetividades dos registros, isto é, adentrar nas motivações emocionais. Colling et al. (2019, p. 37-38) asseveram que há que se ter cuidado com 'leituras rápidas' das quais se descuidam pelas vias da transposição de interpretação anacrônica, bem como descabidas às normas sociais que foram construídas e que governavam os corpos naquele contexto. É preciso considerar que os nossos parentes mais antigos tinham "suas próprias leis e normas. Normas que, se obviamente precisam dos indivíduos para poderem se concretizar, ditam a esses indivíduos como devem ser atualizadas e materializadas" (Souza, 2015, p.78). 
Figura 7: Cena esquemática de bestialidade entre homem e alce na Angermânia, Suécia.

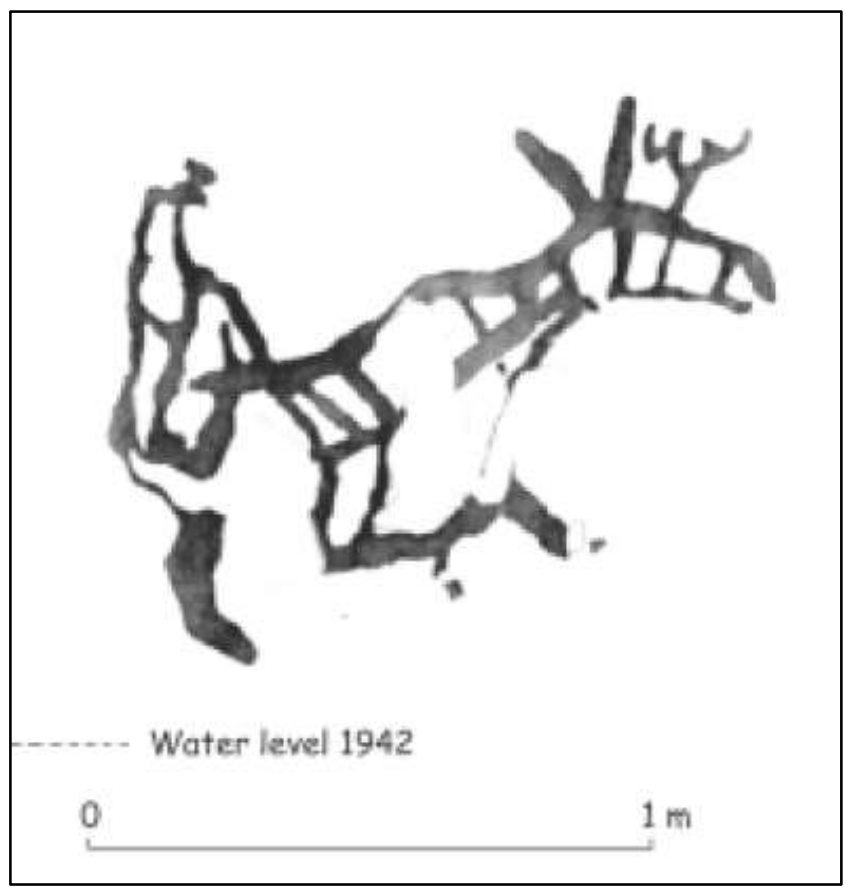

Fonte: Bolin, (2000, p. 163).

No mundo ancestral, muitos artefatos atribuídos a representações de mulheres, em diversas técnicas, foram analisados dentro do universo cultural simbólico ocidental (Perelló, 1986). No antigo Egito, geralmente as pinturas, as estatuetas e esculturas apresentam as delineações femininas com sinuosas curvas, demarcando as dimensões de suas nádegas e cinturas e com seus seios representados de forma acentuada (Domínguez-Rodrigo, 2011). Timothy Taylor (1997, p. 123) indica que as representações de vulvas pintadas nas rochas, datadas de mais de 12 mil anos atrás, especialmente nas cavernas europeias, poderiam ter conotações eróticas e ou rituais. Gunn e Lowish (2017, p. 199) exibem a forma para o sexo feminino encontrada em Nawarla Gabarnmung, Austrália. O Quadro 2 mostra representações do feminino em alguns sítios no mundo.

Quadro 2: Representações do feminino: à esquerda, uma estalactite em Chauvet, na França (A); esquema de pinturas rupestres e pinturas in situ, em Nawarla Gabarnmang, na Austrália (B); à direita, no alto, esquema de antropomorfos femininos no Vale Camonica, na Itália (C); figuras com uma vagina, do sudoeste dos Estados Unidos.

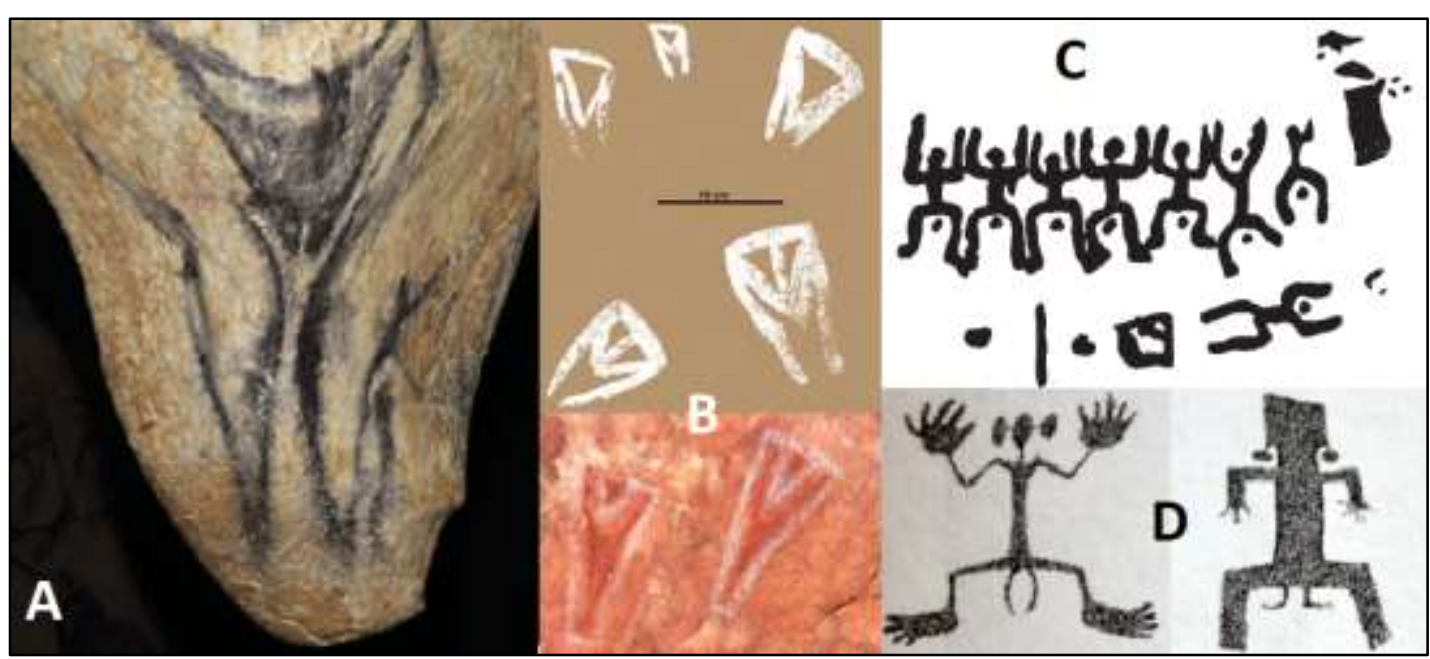

Fontes: Fritz e Tosello, (2015, p. 27); Gunn e Lowish, 2017, p. 199); Bevan, (2015, p. 30); Hays-Gilpin, (2004, p. 27) apud The Arctic University of Norway, (2014, p. 40). 
Taylor (1997), outrossim, ressalta a existência de bastões 'fálicos', como vemos no Quadro 3 a seguir, alguns com representações nítidas de pênis, às vezes mais de um no mesmo objeto. Aqueles que eram feitos de marfim ou de ossos, por exemplo, poderiam servir para inserção vaginal, oral, anal, entre outras. A Figura do pênis ereto está identificada a homens em diversos sítios (Sansoni \& Gavaldo, 2015, p. 132; Goldhahn \& Fuglestvedt, 2012), e por vezes associa-se a desenhos de animais, como de veados com chifres (Bradley, 2009, p. 189) e, por outras, a armas (Goldhahn \& Fuglestvedt, op. cit., p. 245), ou em contextos de violência e guerra, como vemos na Figura 8. Verit (2017, p. 554) aponta para a indicação do falo para baixo, com a mesma extensão das pernas. Angulo e García-Díez (2009, p. 11) atestam que, das 702 representações humanas de tamanho completo da arte paleolítica europeia, apenas 27 , ou 3,85\%, são de ereções.

Quadro 3: Representações do masculino: à esquerda, Figura itifálica em Tassili, na Argélia (A); representações masculinas de figuras rupestres no Parque Nacional de Talampaya, na Argentina (B); Figura rupestre masculina em Trans-Pecos, no Texas, Estados Unidos (C).

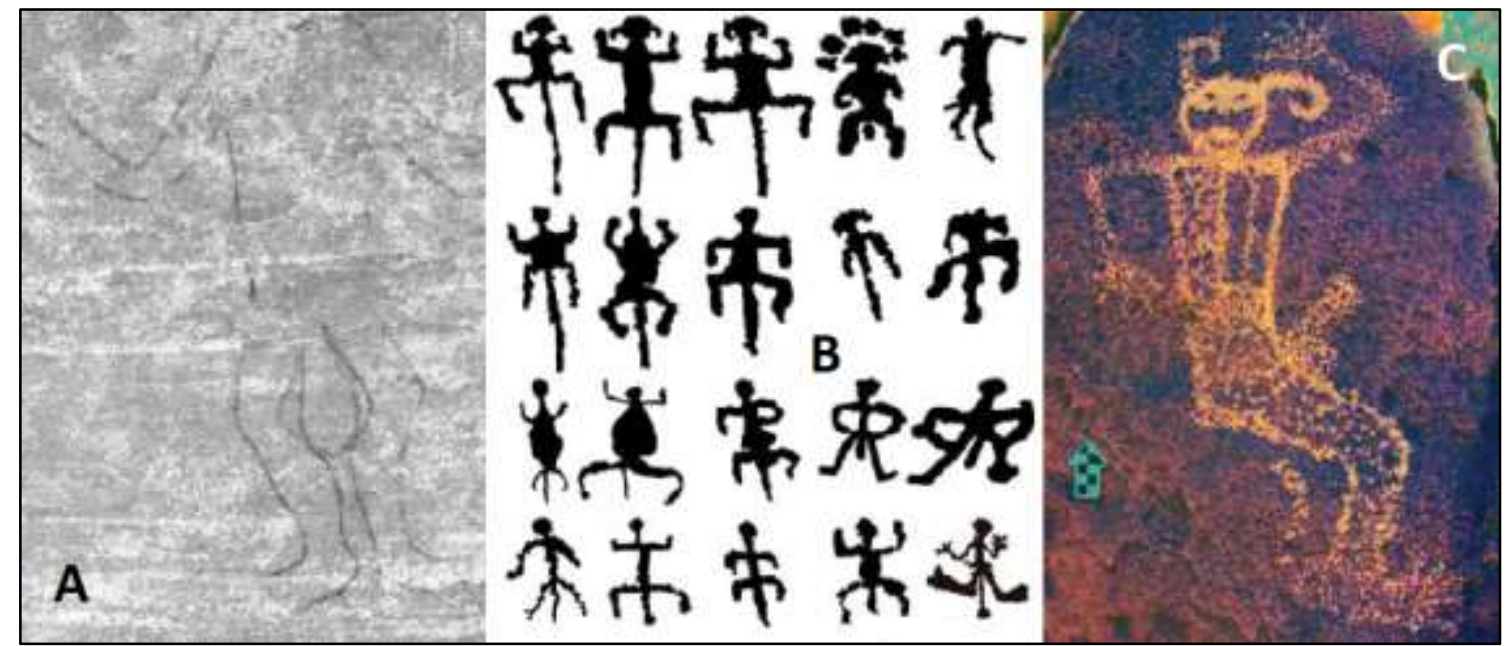

Fontes: Soukopova, (2017, p. 72); Vidal, Ferraro e Pagni, (2016, p. 84); Hampson, (2011, p. 285). 
Figura 8: Representações do masculino em contexto de violência e/ou guerra no Parque Nacional de Naquane, no Vale Camonica, Itália.

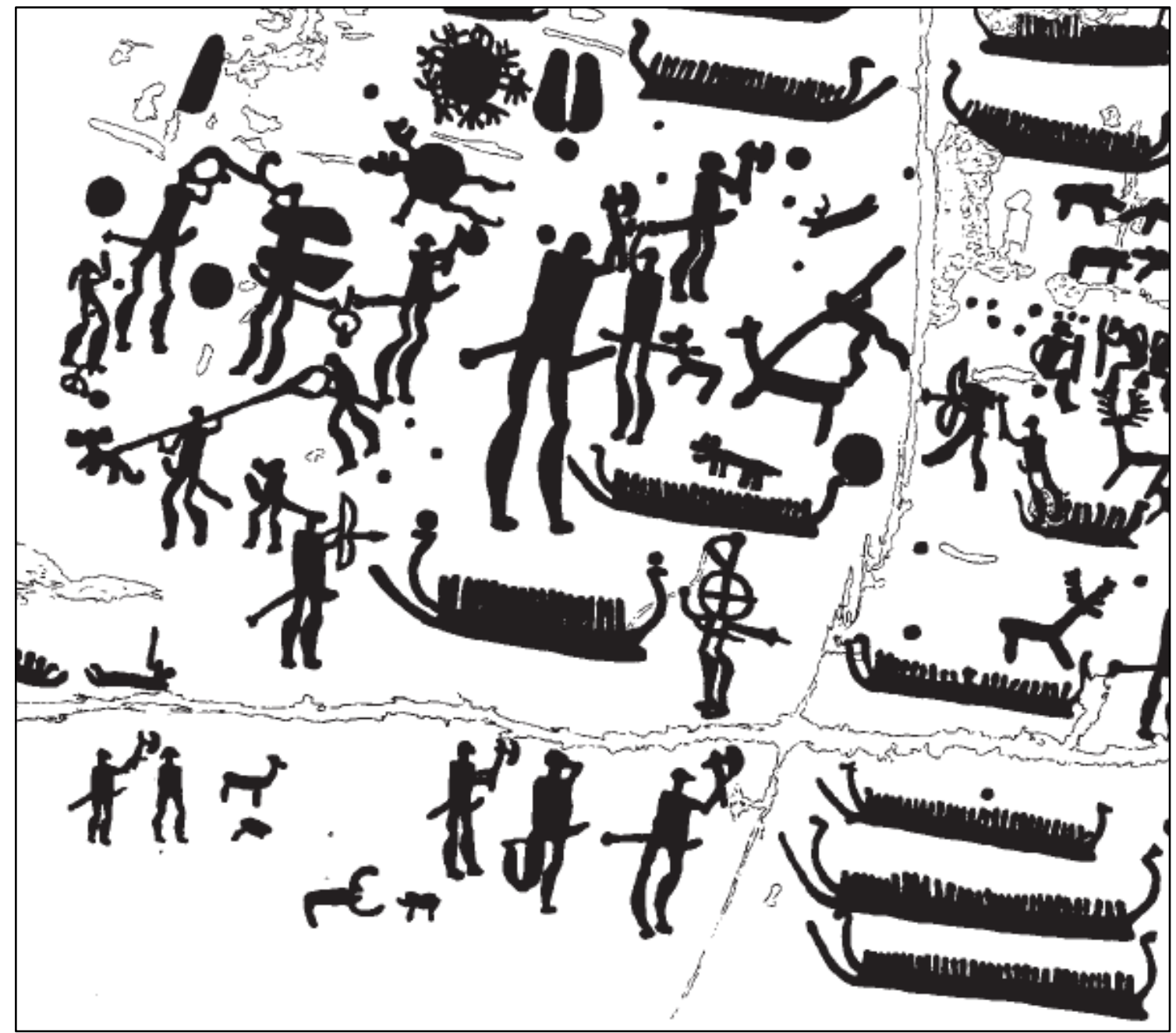

Fonte: Ling e Cornell, (2010) apud Bevan, (2015, p. 22.

Com base no exposto acima, vejamos agora como a sociabilidade e a sexualidade pré-históricas são retratadas nos registros rupestres do PNSC, a fim de estabelecer um diálogo com as referências utilizadas e apontar novas possibilidades de pesquisa.

\section{Resultados e Discussão}

Desde os anos de 1970, o PNSC tem sido local de estudos e reflexões sobre a presença humana ancestral e suas respectivas ações e produções sociais. Tal investimento científico se iniciou com a Missão Francesa, liderada, à época, por Niède Guidon (1991), com apoio de outros pesquisadores e de alguns moradores. Na região, têm sido realizadas inúmeras pesquisas arqueológicas, paleontológicas, educacionais e ambientais e este lugar ainda reserva muitas descobertas para a ciência. Dada a sua importância, o parque recebeu o reconhecimento da comunidade acadêmica a partir dos resultados alcançados pelas pesquisas realizadas na região, especialmente nos estudos cujo objeto são as artes rupestres (principalmente as pinturas). Essas pesquisas contribuíram para a elevação do PNSC à categoria de Patrimônio da Humanidade pela UNESCO, em 1991 (Pessis, 2013).

$\mathrm{O}$ parque e suas áreas adjacentes possuem valiosos e variados vestígios arqueológicos. Foram encontradas ossadas e representações rupestres de diversos animais, alguns ainda viventes na região, outros extintos (Almeida, 2011; Almeida, Rampaneli \& Etchebehere, 2017; Queiroz et al., 2020), além de ossadas humanas dos grupos ancestrais, produções cerâmicas 
antiquíssimas e materiais líticos - pedras lascadas. Esses são os motivos da maior disputa arqueológica dos últimos anos nas Américas, porque apontam para o povoamento em terras brasilis num período anterior ao que apontavam pesquisas já realizadas (Etchevarne, 1999-2000; Adovasio \& Page, 2011). Independentemente das polêmicas dos materiais líticos que já foram encontrados, as pinturas rupestres são os vestígios históricos que mais saltam aos olhos de qualquer visitante, turista e /ou pesquisador (Meltzer, Adovasio \& Dillehay 1996; Justamand, Funari \& Alárcon-Jiménez, 2018). De acordo com os métodos de datação aplicados, os registros do PNSC atingem mais de 10 mil anos (Pessis, Cisneiros \& Mutzenberg, 2013), isto é uma parcela do tempo importante para a história dos povos e sobretudo para os nossos ancestrais.

Atualmente estão catalogados 1.335 sítios arqueológicos no local, 184 sítios com vestígios cerâmicos, 946 sítios de pinturas rupestres, 206 sítios de pinturas e gravuras e 80 sítios de gravuras (Guidon, 2014a, 2014b; Maranca \& Martin, 2014). Esses locais, a nosso ver, abrangem muito mais do que a catalogação e marcação de tamanho e cores dessas imagens; pensamos que nelas estão contidas histórias e processos a serem revelados. Histórias que têm importância para se refletir o hoje (Guidon, 2014a, 2014b), inclusive no que tange aos processos de escolarização (Negreiros, 2015 e Gomes Filho \& Justamand, 2018) e talvez o binarismo e dimorfismo de gênero que fundamenta a atual história da sexualidade como discutiram Colling et al. (2019). As particularidades do PNSC consistem em ser o maior enclave de sítios do mundo (Oliveira, Justamand \& Funari, 2019, p. 81), em uma permanência de ocupação de um território de milhares de anos e em uma diversidade de temáticas impressionante, ressaltando-se a da sexualidade, com recorrências de relações heterossexuais e homossexuais, de bestialidade ou zoofilia, e até mesmo de possíveis práticas de violações sexuais (Justamand et al., 2019; Justamand et al., 2020).

A temática da sexualidade se tornou alvo de debates, mesmo que ainda tênues, em alguns manuais e artigos, apesar de sua presença significativa nas inscrições do PNSC. No livro Comunicar e Educar no território brasileiro: uma relação milenar foi tratada a questão, especialmente, comparando-se as imagens do PNSC com a de outras partes do país (Justamand, 2012). Um trabalho relevante intitulado O Brasil desconhecido: as pinturas rupestres de São Raimundo Nonato - Piauí, desnudou os gestuais rupestres com cenas de penetração, excitação masculina coletiva e sexo grupal; e outra publicação discutiu a presença dos falos e sua representação em grupos (Justamand, 2010, 2011). Há ainda trabalhos com comentários acerca de falos, vulvas e sexo com mulheres grávidas (Justamand, 2014a, 2014b, 2015; Justamand \& Funari, 2014, 2016, 2017; Justamand, Funari \& Alarcón-Jiménez, 2016). O homoerotismo foi abordado por Negreiros (2015) e a sexualidade pré-histórica por Lira (2017).

Gabriela Martin (1984), uma das pesquisadoras mais antigas da Fundação Museu Homem Americano (FUMDHAM), publicou um dos primeiros trabalhos a se distanciar das metodologias que cartografaram e caracterizaram as tradições, subtradições e estilos sobre as pinturas rupestres do parque. A autora (loc. cit., 1999) priorizou a interpretação de temáticas tratando de amor, violência e solidariedade, ou seja, problematizando as possíveis imaterialidades contidas na concretude dos traços presentes nas rochas, e tem acompanhado os trabalhos desde os anos 1970. Para ela, as pinturas rupestres do PNSC seriam referências no entendimento da sequência de ocupação humana naquele território.

Outra pesquisadora fundamental para os trabalhos no PNSC é Anne Marie-Pessis, que publicou juntamente com Martin (Pessis \& Martin, 2014) um trabalho em que ressaltam o movimento das composições de pinturas rupestres. Apesar de discordarem de certas interpretações das imagens rupestres, indicam que há cenas de lutas, caças, muitos animais, danças e práticas sexuais e que as inscrições nas rochas possuem uma técnica com traço leve e seguro. Nos casos em que há diferenciação genital, o sexo é indicado pelo pênis para os homens, tanto ereto quanto flácido; e o círculo abaixo das pernas para indicar as vulvas, demarcação, em alguns casos, das mulheres (Pessis, 2003, p. 116-7; Prous, 2006, p. 73; Alárcon-Jiménez et al., 2017, p. 46). Essa abordagem descrita por Pessis e Martin (2014), a qual apresenta linearidade de sentidos entre sexo e gênero, fez parte da corrente da Arqueologia de Gênero analisada por Silva, Castro e Lima (2011).

Boa parte dos trabalhos, que se deslocam da arqueologia pós-processual, pautam-se em potencializar as análises das ambiguidades nos corpos representados na pintura rupestre em diferentes sociedades por meio da dicotomia e binarismo de 
gênero. Assim, apresentam em seus resultados de pesquisa possíveis organizações sociais que apresentam o gênero essencializado e bipolar: masculino/feminino, homem/mulher. Pessis (2013, p. 128) afirma que há três formas de identificação sexual - a ausência de definição, o falo e "traços que permitem identificar o sexo feminino". Ademais, no "conjunto das figuras da Tradição Nordeste existe total ausência da representação do sexo feminino, tal como ele é morfologicamente", uma vez que "o que deve ser salientado é a função" receptora do falo.

Entre as grandes regiões rupestres do Brasil, destacam-se a presença no PNSC a Tradição Geométrica, a Tradição Nordeste, "definida por Niède Guidon a partir de sítios do Piauí", e a Tradição Agreste, não considerada como tradição singular por Prous (1992, pp. 521; 525). Na Tradição Nordeste, há duas subtradições, a Salitre e a Várzea Grande. Os padrões de registros de antropomorfos no PNSC são mostrados nas figuras 9 e 10 em seguida. Por sua vez, a subtradição Várzea Grande compreende três outros estilos: Serra da Capivara, Serra Branca e complexo Serra Talhada (Guidon, 1985, p. 15-40). As cenas de sexo estão presentes em toda a subtradição Várzea Grande (Prous, 1992 Valls, 2007; Oliveira, 2013), como podemos ver nas figuras 11, 12 e 13 a seguir, mas ausentes na subtradição Salitre, a qual, para Morales Jr. (2005, p. 28), deveria ser considerada um estilo próprio.

Figura 9: Registros rupestres de antropomorfos no sítio arqueológico da Toca do Barro, no PNSC (Tradição Nordeste, subtradição Várzea Grande).

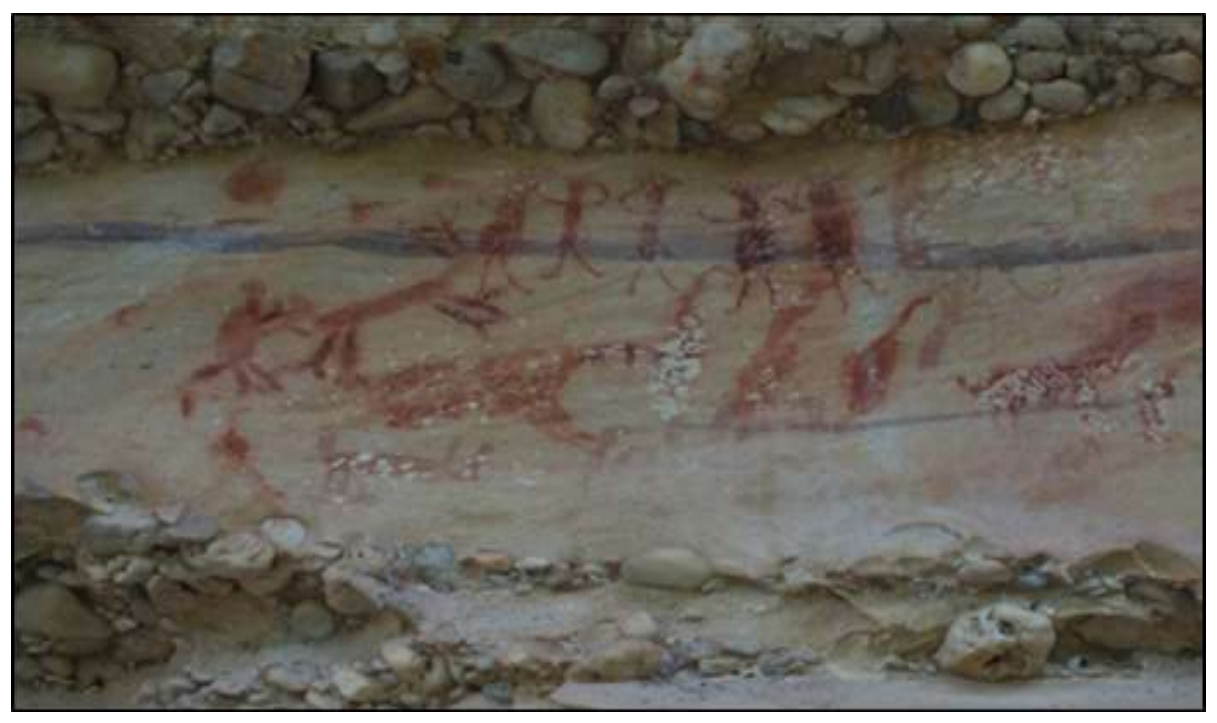

Fonte: Oliveira, (2018, p.277).

Figura 10: Registros rupestres de antropomorfos no sítio arqueológico da Toca da Entrada do Baixão da Vaca, no PNSC (Tradição Nordeste, subtradição Várzea Grande).

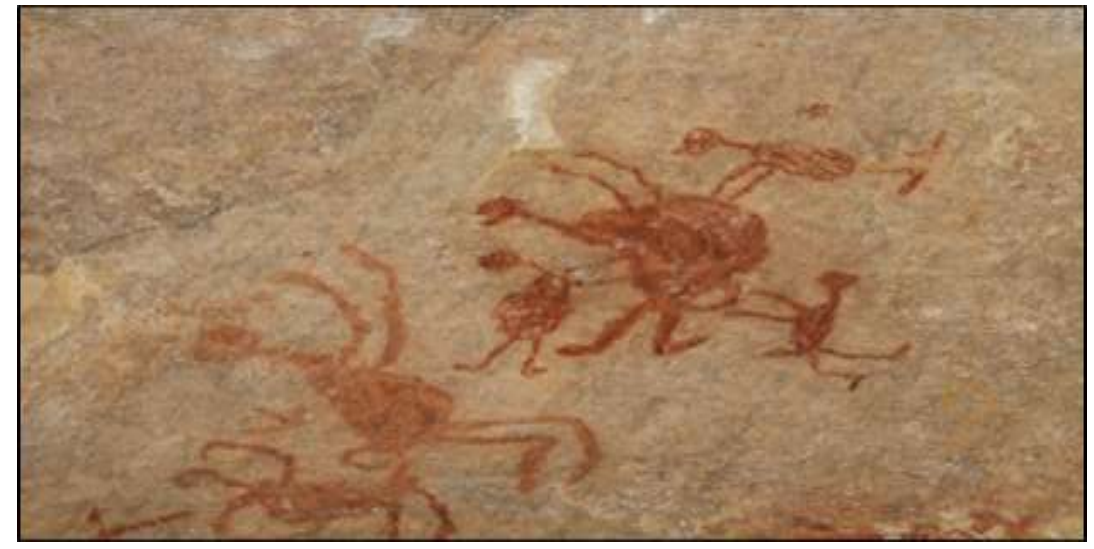

Fonte: Oliveira, (2018, p. 269). 
Figura 11: Registros rupestres com cenas de sexo no sítio arqueológico da Toca do Boqueirão da Pedra Furada, no PNSC (Tradição Nordeste, subtradição Várzea Grande).

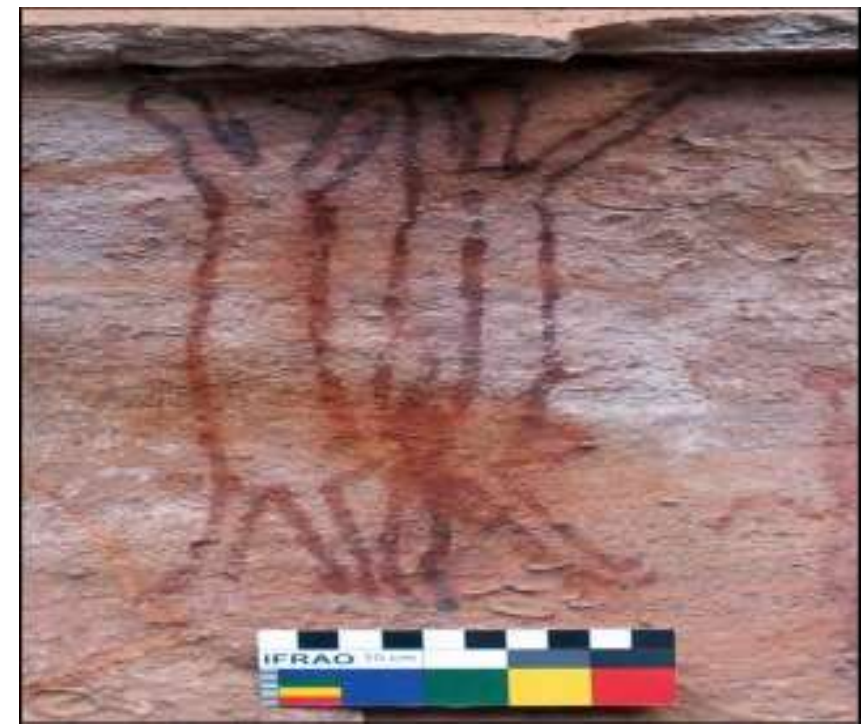

Fonte: Acervo pessoal do pesquisador Gabriel Oliveira.

Figura 12: Registros rupestres com cenas de sexo no sítio arqueológico da Toca do Boqueirão da Pedra Furada, no PNSC (Tradição Nordeste, subtradição Várzea Grande).

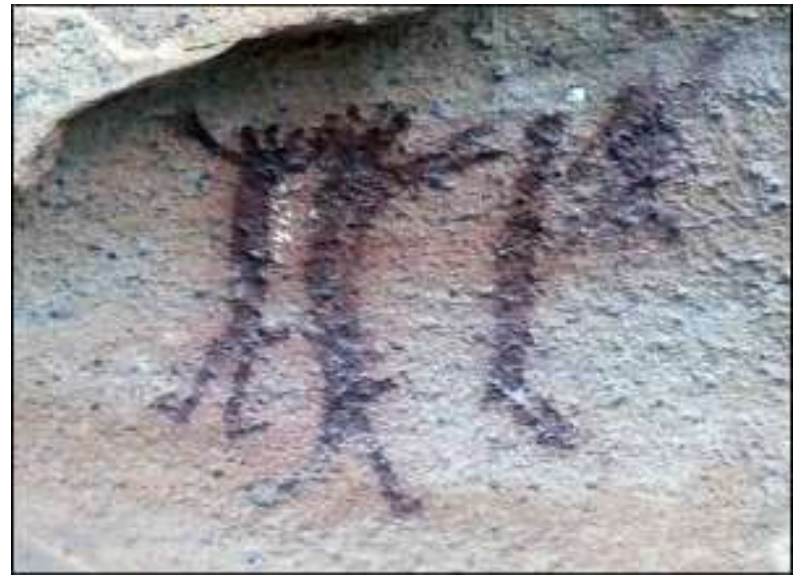

Fonte: Acervo pessoal do pesquisador Gabriel Oliveira.

Figura 13: Registros rupestres com cenas de sexo no sítio arqueológico da Toca da Entrada do Baixão da Vaca, no PNSC (Tradição Nordeste, subtradição Várzea Grande).

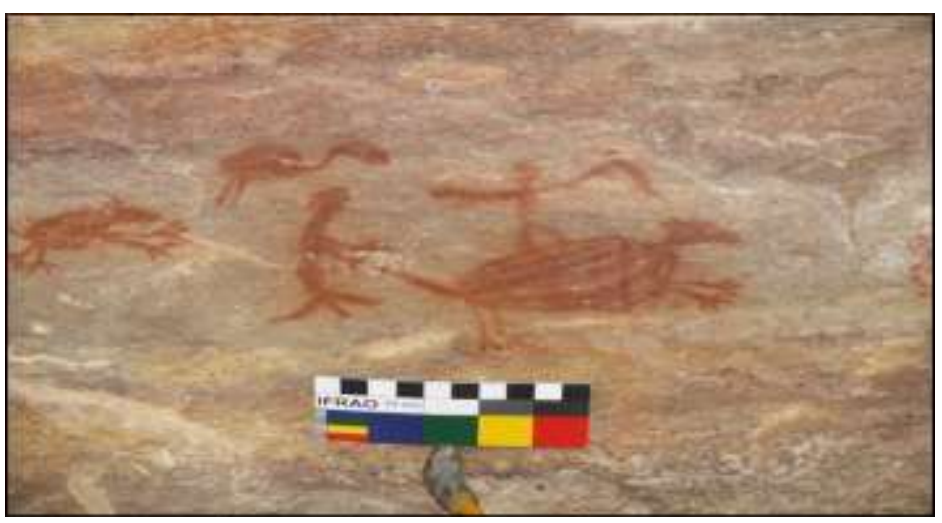

Fonte: Acervo pessoal do pesquisador Gabriel Oliveira. 
Luiza Castro (2010) analisou cenas sexuais na Toca do Baixão da Vaca, na Toca da Entrada do Pajaú, na Toca do Pinga do Boi, na Toca do Caldeirão dos Rodrigues I, na Toca do Sobradinho I, na Toca do Baixão do Perna IV e na Toca do Inácio II. A autora assegura que "o tema sexualidade apresenta a sua maior expressão no estilo Serra da Capivara" (ibid.: 66), formando "pares e também conjuntos com mais de três componentes" (loc. cit.). Cita ainda que a representação antropomórfica masculina “é recorrente e a representação da vulva é recorrente apenas no contexto de cenas de sexo ou de parto e apresenta-se em forma de círculo ou semicírculo na parte inferior das pernas das figuras femininas" (loc. cit.).

Ademais, nas cenas analisadas, "a relação com penetração por trás aparece com frequência, considerada um padrão cenográfico recorrente", encontrando-se, ainda cenas com alternância entre a Figura feminina por cima da masculina durante o ato sexual problematizando as finalidades das práticas sexuais para além da reprodução da espécie (Colling et al., 2019). Na Figura 14, vemos um exemplo de pintura rupestre em que não há diferenciação sexual.

Figura 14: Registros rupestres em que não há indicação de sexo no sítio arqueológico da Toca do Caldeirão dos Rodrigues I, no PNSC (Tradição Nordeste, subtradição Várzea Grande).

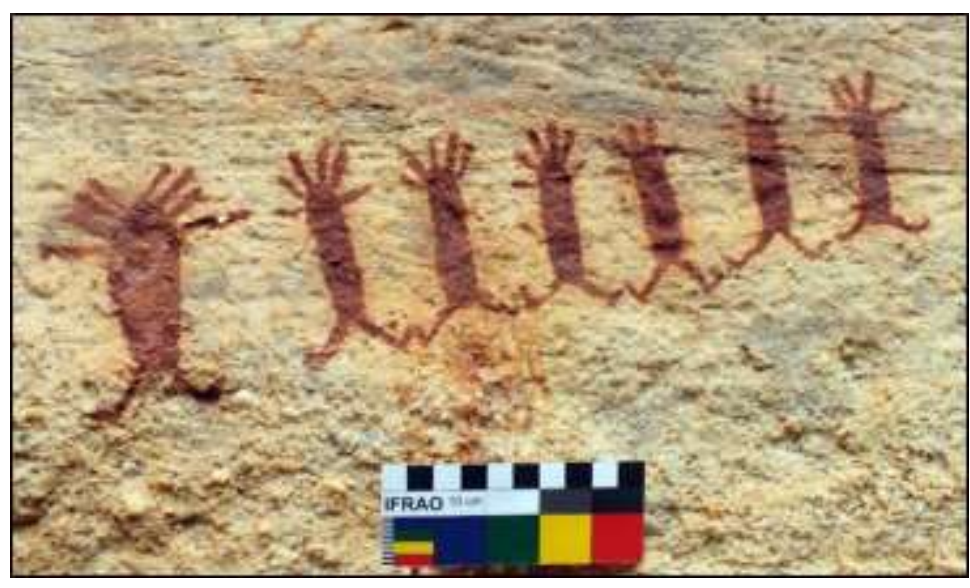

Fonte: Oliveira, (2018, p. 343).

Nas figuras 15 e 16, vemos representações do falo no PNSC; nas figuras 17 e 18, representações do feminino sem qualquer vinculação com o ato sexual, contrapondo a percepção de que o feminino se subordinaria, aparentemente, a este e ao parto. As figuras 19 e 20 trazem pinturas em que o feminino está vinculado ao sexo heteronormativo, como poderíamos nomeálo com o olhar contemporâneo. Nesse sentido, o trabalho de Castro (op. cit.) filia-se a outros dois - o de Buco (2013) e o de Pessis (2013), contrapondo-se às hipóteses de Justamand, Funari e Alarcón-Jiménez (2016) e de Justamand et al. (2017). Para Buco (op. cit.: 66), na Toca da Entrada do Baixão da Vaca, "pode-se ver uma tripla diferenciação sexual”, com "figuras masculinas, em que o pênis está representado em repouso ou em ereção"; com "figuras femininas, em que a vulva é representada na forma de uma cavidade exteriorizada por um círculo ou semicírculo"; e com "figuras assexuadas, em que não existe diferenciação sexual manifestada". 
Research, Society and Development, v. 10, n. 8, e43610817095, 2021

(CC BY 4.0) | ISSN 2525-3409 | DOI: http://dx.doi.org/10.33448/rsd-v10i8.17095

Figura 15: Registros rupestres com representação do falo no sítio arqueológico da Toca da Entrada do Pajaú, no PNSC (Tradição Nordeste, subtradição Várzea Grande).

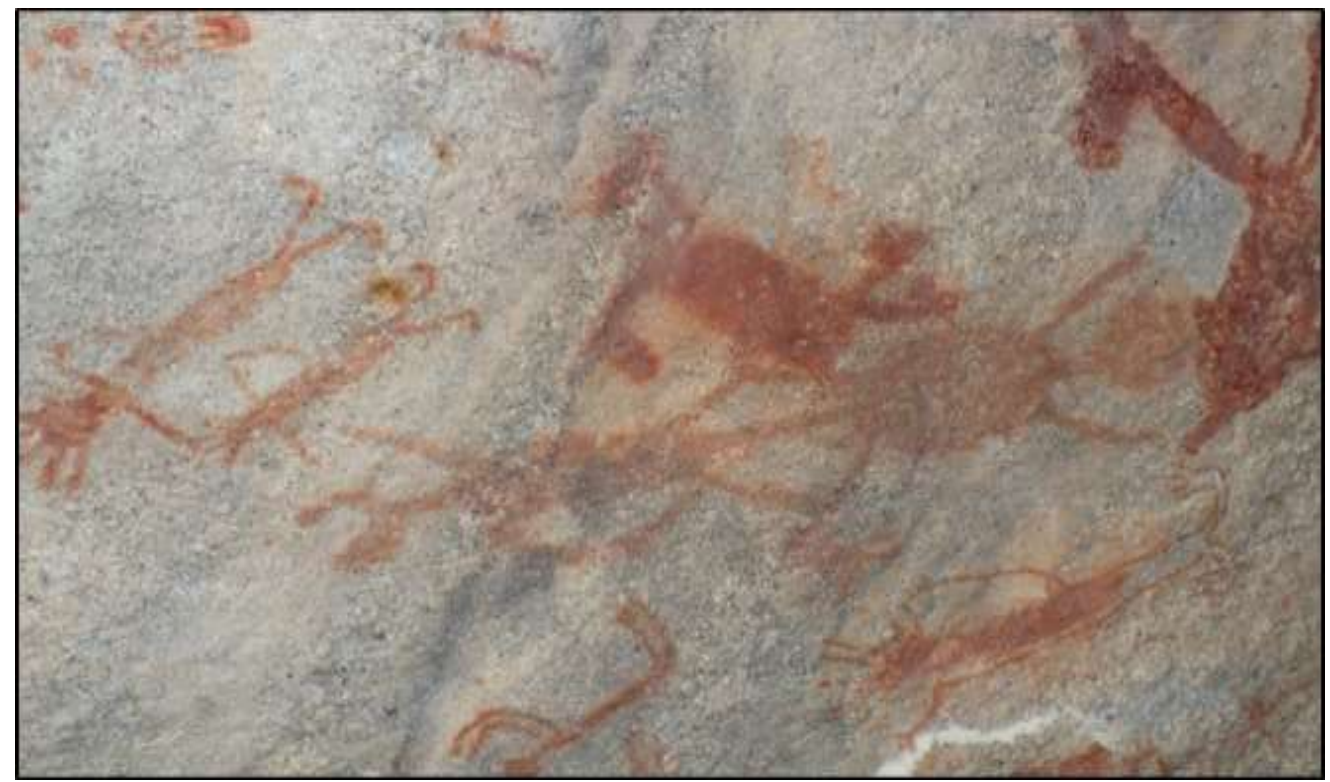

Fonte: Acervo pessoal do pesquisador Gabriel Oliveira.

Figura 16: Registros rupestres de figuras com falos no sítio arqueológico da Toca do Boqueirão da Pedra Furada, no PNSC (Tradição Nordeste, subtradição Várzea Grande).



Fonte: Acervo pessoal do pesquisador Gabriel Oliveira. 
Figura 17: Registros rupestres do sexo feminino representado por meio de dois antropomorfos um virado de costas para o outro, entre eles a presença de um símbolo do órgão feminino no sítio arqueológico da Toca do Barro, no PNSC (Tradição Nordeste, subtradição Várzea Grande).



Fonte: Acervo pessoal do pesquisador Gabriel Oliveira.

Figura 18: Registros rupestres que retratam o feminino representado por dois antropomorfos um virado de costas para o outro, entre eles a presença de um símbolo do órgão feminino no sítio arqueológico da Toca do Veredão VIII, no PNSC (Tradição Nordeste, subtradição Várzea Grande).

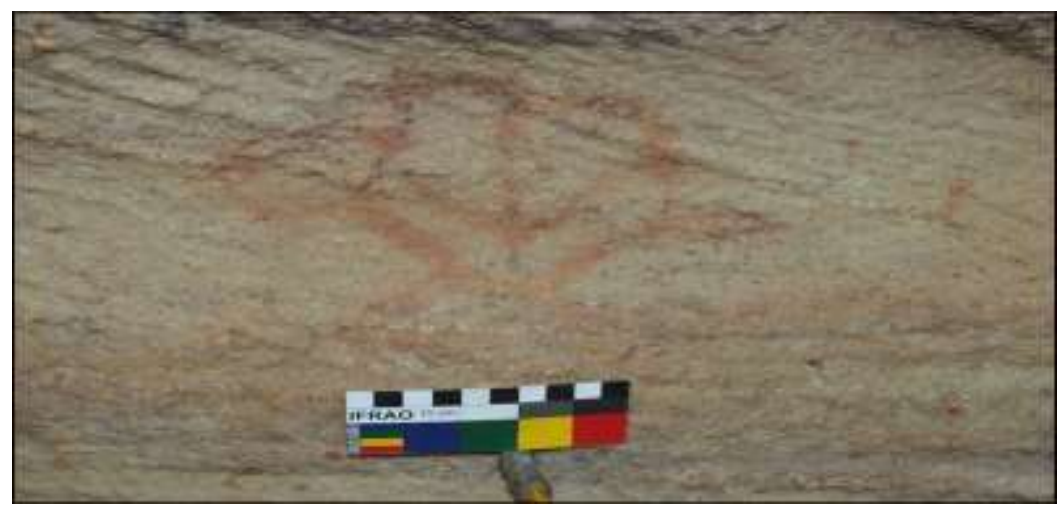

Fonte: Acervo pessoal do pesquisador Gabriel Oliveira.

Figura 19: Registros rupestres com representação do feminino vinculado ao ato sexual no sítio arqueológico da Toca do Paraguaio, no PNSC (Tradição Nordeste, subtradição Várzea Grande).

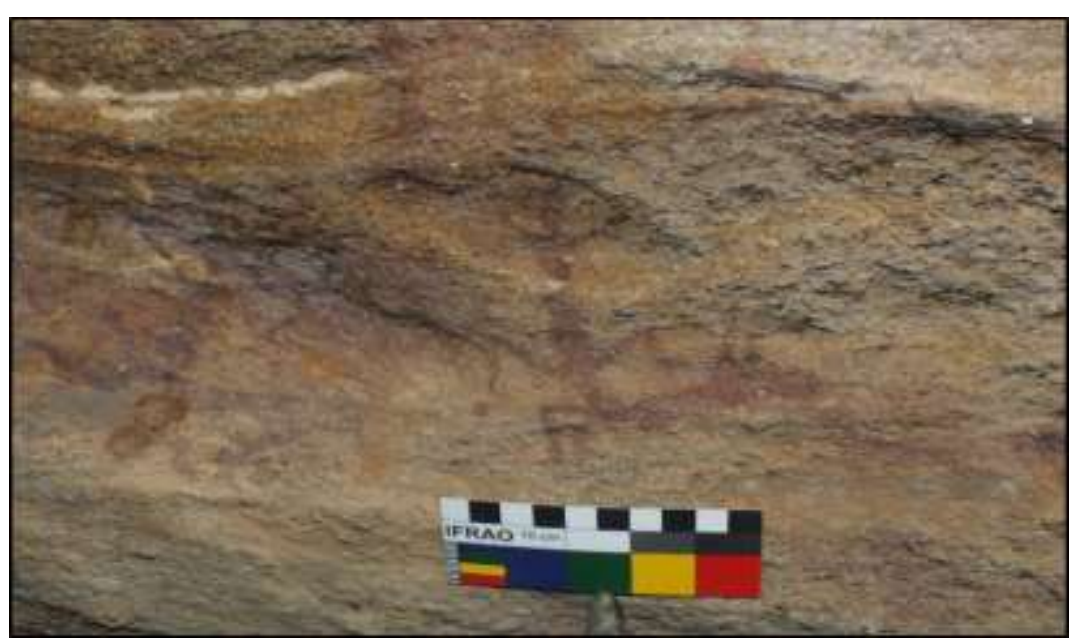

Fonte: Oliveira, (2018, p. 264). 
Figura 20: Registros rupestres com representação do feminino vinculado ao ato sexual no sítio arqueológico da Toca do Caldeirão dos Rodrigues I, no PNSC (Tradição Nordeste, subtradição Várzea Grande).

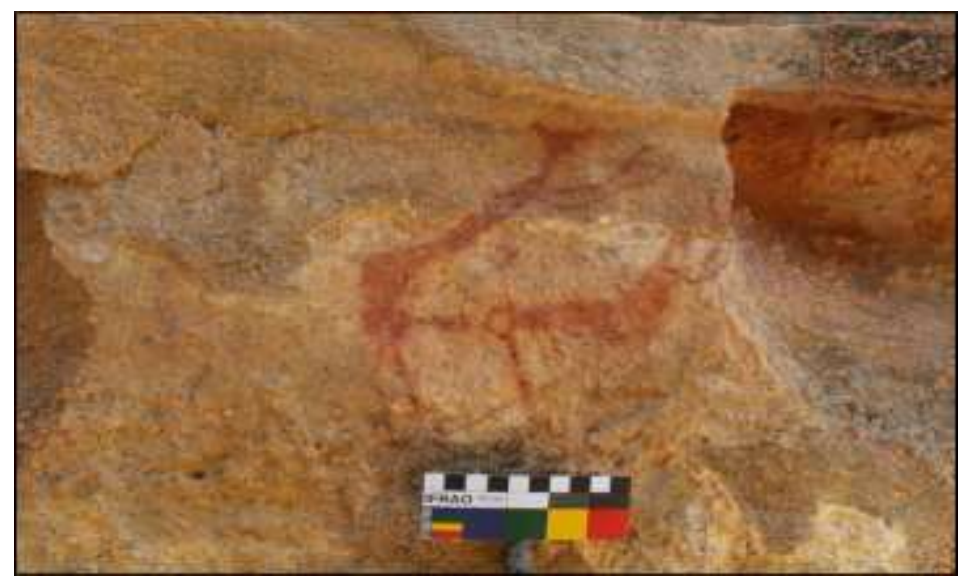

Fonte: Oliveira, (2018, p. 341).

Isso nos interessa porque nos permite pensar por que os pré-históricos, por exemplo, não diferenciariam a vulva do ânus, retratando com dois signos diferentes - ânus círculo e vulva semicírculo - o feminino, conforme apontado por Lira (2017). Desse modo, temos, com base na bibliografia citada, duas representações para um mesmo significado. Se não temos mecanismos de compreensão exata do que se passava na pré-história, e se considerarmos que o feminino é representado por dois significantes distintos, poderíamos pensar que talvez essa duplicidade fosse característica de que o falo não exerce primazia nessa sociedade (o masculino subordinado ao feminino ou com função específica subordinada) e que as distinções sexuais seriam secundárias.

Por outro lado, isso nos remete ao pensamento lacaniano (Bonfim, 2014), que assegura que um único significante apresenta dois significados desde que a base da relação seja fálica - o falo é simbolizado pela sua presença, indicativa do masculino, e pela sua falta, indicativa do feminino. Ao indiferenciar círculo e semicírculo, como possíveis categorias de ato sexual, submete-se a representação da sexualidade da pré-história à sexualidade falocêntrica, explicitada na percepção limitada de que o feminino se resume ao não-masculino, à falta do pênis (nas imagens, aquelas que não dispõem de pênis) e de que a vulva somente é representada em função do ato sexual, o que, por sua vez, é contestado por Justamand, Funari e Alarcón-Jiménez (2016) e por Justamand, Alarcón-Jiménez, Oliveira e Funari (2017). Nesse sentido, ressaltamos que há diversas pinturas rupestres em que o signo sexual não é relevante e, portanto, não é verdadeiro que a ausência do falo significa necessária e afirmativamente tratar-se do feminino (Lira, 2017).

As cenas de sexo são mais abundantes e frequentes que as de parto nos registros rupestres do PNSC (Oliveira, 2018), como vemos na Figura 21, em que é possível interpretar o nascimento de uma criança auxiliado por outra pessoa, talvez uma “parteira”. Nesse contexto, isso pode demonstrar que os grupos humanos que ali habitavam estavam preocupados com o nascimento dos seus filhos, sendo o parto uma atividade realizada em grupo. Há uma coletividade para o evento do nascimento, com uma única Figura próxima, ligada à parteira, enquanto os outros estão dispostos em movimentação, possivelmente eufóricos ou em alguma dança ritualística. O corpo que dá à luz ainda se mantém em seu formato de gravidez, com a circunferência corporal. 
Figura 21: Registros rupestres com representação de nascimento no sítio arqueológico da Toca do sítio do Meio, no PNSC (Tradição Nordeste, subtradição Várzea Grande).



Fonte: Acervo pessoal do pesquisador Gabriel Oliveira.

Em relação à bibliografia citada é interessante perceber que há uma preocupação de cientistas em encontrar pinturas rupestres que rompam com determinada perspectiva que invisibiliza a diversidade sexual, especialmente o homoerotismo. Justamand, Funari e Alarcón-Jiménez (2016, p. 41) não trazem em seu trabalho registro rupestre que seja atribuído ao homoerotismo, embora em uma pintura rupestre na Toca do Caldeirão do Rodrigues I haja dois antropomorfos na Figura 24, um em posição de penetrar o animal e segurando o pênis do outro - cabe ressaltar se essa imagem representaria também um comportamento homoerótico entre duas figuras masculinas, como vemos na Figura 22. Outra ocorrência de bestialidade no PNSC é apresentada na Figura 23 subsequente.

Figura 22: Registros rupestres com bestialidade e homoerotismo no sítio arqueológico da Toca do Caldeirão do Rodrigues I, no PNSC (Tradição Nordeste, subtradição Várzea Grande



Fonte: Acervo pessoal do pesquisador Gabriel Oliveira. 
Figura 23: Registros rupestres de bestialidade na Toca do Sítio do Meio, no PNSC (Tradição Nordeste, subtradição Várzea Grande).

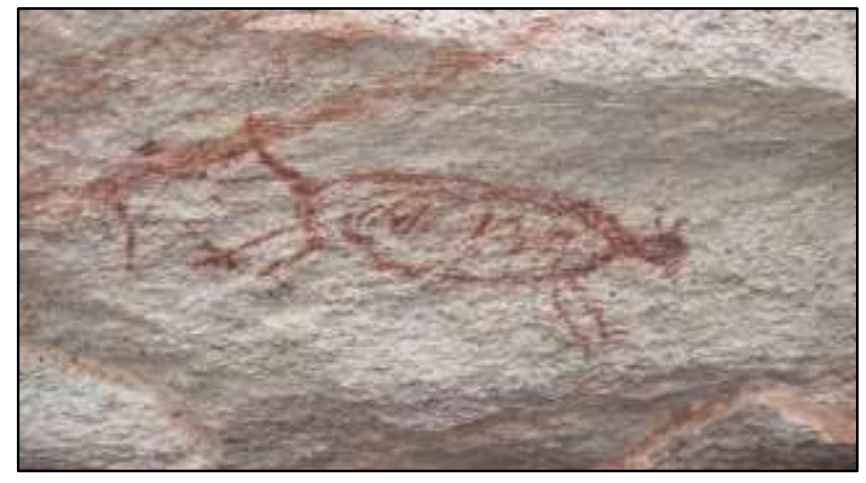

Fonte: Acervo pessoal do pesquisador Gabriel Oliveira.

O homoerotismo está presente em alguns outros sítios no PNSC. Neste trabalho apresentamos mais duas possíveis cenas com esta temática em nosso local de pesquisa, como vemos nas figuras 24 e 25 . Em geral, as representações que possibilitam tal interpretação dependem da presença de bastões fálicos. Nash (2001, p. 53) afirma que "embora não identificável na arte rupestre, não se pode negar que a homossexualidade feminina fosse praticada". Kendirci, Kadığlu, Şerefoğlu e Çayan (2014, p. 117) reiteram que a informação sobre a prática homossexual feminina é escassa. Contudo, acreditamos que há a possibilidade de considerar uma cena existente na Toca do Sítio do Meio como homoerotismo feminino, como vemos na Figura 26 . Na cena da Figura de 26, observar-se dois antropomorfos em oposição de costa uma para outro, destarte, entre a presença um símbolo do órgão feminino, a uma espécie de "vulva" entre ambos, nota-se a presença do lábios vaginas divididos pelo corpo do clitóris.

Figura 24: Registros rupestres com possível interpretação homoerótica no sítio arqueológico da Toca do Boqueirão da Pedra Furada, no PNSC (Tradição Nordeste, subtradição Várzea Grande).

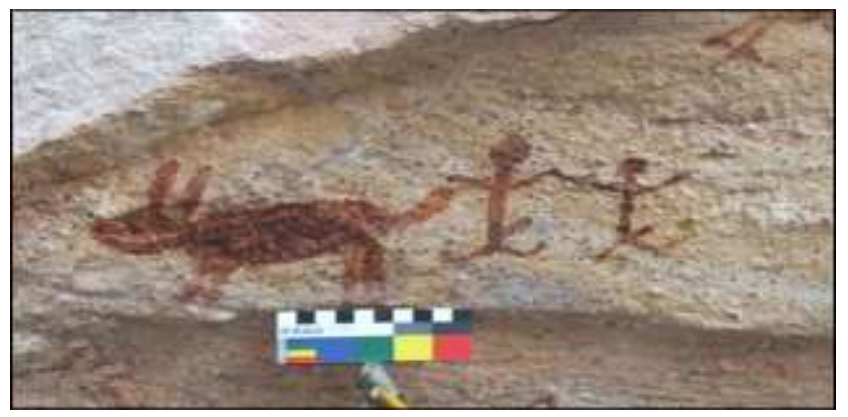

Fonte: Acervo pessoal do pesquisador Gabriel Oliveira. 
Figura 25: Registro rupestre com possível interpretação homoerótica, com cena de falos eretos e de homens com seus falos um de frente para o outro no sítio arqueológico da Toca do Caldeirão dos Rodrigues I, no PNSC (Tradição Nordeste, subtradição Várzea Grande).

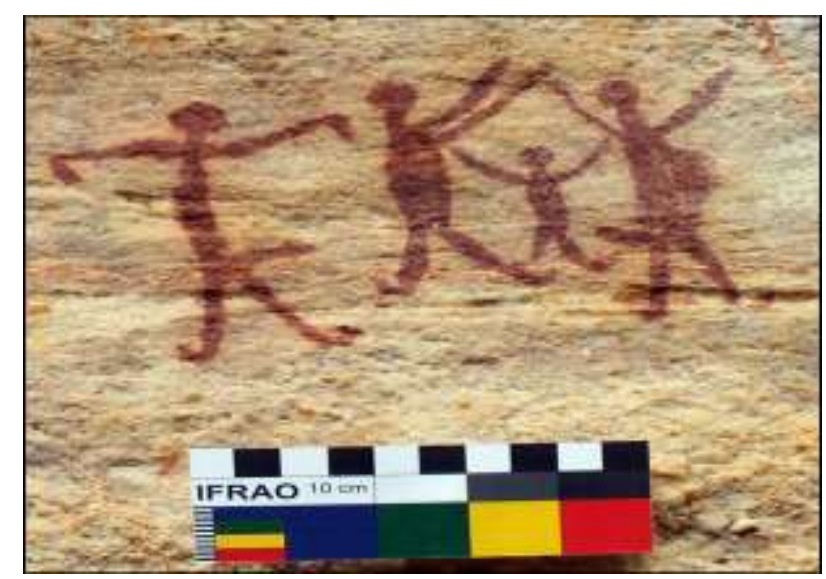

Fonte: Oliveira, (2018, p. 340).

Figura 26: Registro rupestre com possível interpretação homoerótica feminina no sítio arqueológico da Toca do Sítio do Meio, no PNSC (Tradição Nordeste, subtradição Várzea Grande).



Fonte: Acervo pessoal do pesquisador Gabriel Oliveira.

Por fim, no PNSC há cenas da sociabilidade pré-histórica que envolvem o encontro entre nossos ancestrais - encontros muitas vezes encarados como ritualísticos e eventualmente marcados pela violência. A interação entre os grupos humanos ancestrais, como vemos na Figura 27 a seguir, é bastante marcada pela interação com o meio, a fim de convergir esforços para a sobrevivência (OLIVEIRA, 2018). Uma temática recorrente é a das caçadas, em que os grupos agiam coordenadamente para garantir alimentos; entretanto, esses encontros podiam ser desagregadores ou violentos, como sugere a cena do cativeiro exibida na Figura 28 em seguida. Podemos observar pela cena de suposta violência uma retratação de movimentos espelhados, com corpos diferentes em proporção, altura e falo. Na extrema esquerda, o falo possui maior estilização na parte da glande, enquanto o corpo disposto na extrema direita apresenta pouca estilização e menor tamanho e porta um objeto. À frente dos antropomorfos com falos eretos, estão outras figuras apoiadas ou presas a um possível suporte. No centro da cena, observamos um antropomorfo menor em tamanho, comparado aos outros, e seus braços estão levantados e rígidos à direção da ação na extrema direita. 
Figura 27: Registro cena de sociabilidade social no sítio arqueológico da Toca dos Coqueiros, no PNSC (Tradição Nordeste, subtradição Várzea Grande).



Fonte: Oliveira, (2018, p. 354).

Figura 28: Registro rupestre conhecido como Cena do cativeiro, com cinco antropomorfos, no sítio arqueológico da Toca do Caldeirão dos Rodrigues I, no PNSC (Tradição Nordeste, subtradição Várzea Grande).

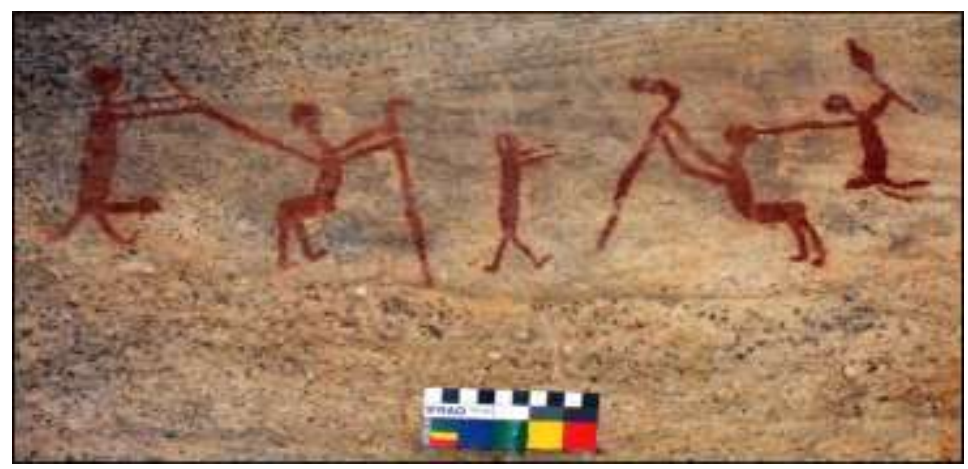

Fonte: Oliveira, (2018, p. 340).

\section{Considerações Finais}

Acreditamos que a nossa contribuição reside na discussão da semiótica e da sexualidade rupestres, por meio de comparações com sítios ao redor do mundo e de indagações a respeito da imaterialidade intrínseca à materialidade dos registros que sobreviveram ao tempo. De fato, nossa abordagem não pretende esgotar as múltiplas possibilidades de discussão sobre essa temática. Todavia, ressaltamos aos leitores que outros estudos foram publicados ao longo dos dois últimos anos, sendo estes indicados para maior compreensão dos desdobramentos e contribuições de nossa expedição. O texto aqui é mais uma sólida contribuição para que os nossos leitores tenham uma ideia, mesmo que fragmentada, do universo afetivo social e sexual pintado nas rochas do PNSC. Indubitavelmente, ainda há muito que ser descoberto, analisado e apresentado à sociedade civil e à comunidade científica.

Nesses escritos nos preocupamos em demonstrar que diversos tipos de cenas existentes em sítios arqueológicos pelo mundo, dentro da temática da sociabilidade e da sexualidade, estão presentes também no PNSC. Tomamos como certo que nossos ancestrais ao registrarem práticas sexuais e ou sociais variadas, em suas artes, demonstram que lidavam, ao que nos parece, com muita naturalidade, com os seus corpos e também com os seus afetos, por mais diferentes e diversos que fossem 
esses desejos e ações sexuais. A sexualidade, em toda a sua diversidade, não era reprimida ou escondida, afinal, as pinturas rupestres estavam ali para todos verem e todos tinham acesso livre a elas. Milênios depois.

\section{Referências}

Adovasio, J. M., et al. Os primeiros americanos. Em busca do maior mistério da arqueologia. Trad. Renato Bittencourt. Record

Adovasio, J. M. et al. Sexo invisível. O verdadeiro papel da mulher na pré-história. Trad. Hermano de Freitas. Record

Aggrawal, A. A new classification of zoophilia. In: Journal of Forensic and Legal Medicine, 73-8.

Alárcon-Jiménez, A., et al. Arqueologia do feminino. A mulher não é só sexo na Serra da Capivara. O feminino nas pinturas rupestres em São Raimundo Nonato - PI. Embu das Artes: Alexa Cultural, 2017

Albuquerque Júnior, D. M. História: A arte de inventar o passado. Ensaios de Teoria da História. Edusc

Almeida, V. J. M. Prováveis Significados Paleoambientais das Pinturas Rupestres Zoomorfas do Parque Nacional Serra da Capivara - PI. 2011 . 134 f. Dissertação (Mestrado) - Curso de Análise Geoambiental, Departamento de Centro de Pós-graduação e Pesquisa em Análise Geoambiental, Universidade de Guarulhos UNG

Almeida, V. J. R., et al. Ambientes pré-históricos: uma interpretação das pinturas rupestres do Parque Nacional Serra da Capivara. Prismas187 p.

Ângulo, J. C. et al. Male genital representation in Paleolithic Art: erection and circumcision before History. In: 24th Annual European Association of Urology Congress, Stockholm, Sweden, 17-21

Araújo, A. G., et al. Parque Nacional Serra da Capivara, Piauí Brasil. Fundação do Homem Americano. São Paulo: Typelaser Desenvolvimento Editorial Ltda, 1998.

Barthes et al. Male Homosexual Preference: Where, When, Why? In: PLoS ONE

Behn, F. et al. Europa pré-histórica. Editorial Verbo

Bevan, L. Hyper-masculinity and the construction of gender identities in the Bronze Age rock carvings of southern Sweden. In: SKOGLUND, Peter; LING, Johan; BERTILSSON, Ulf (ed.). Picturing the Bronze Age. Oxbow Books

Blanc, C. Uma breve história do sexo. Fatos e curiosidades sobre sexo e sexualidade mais interessantes de todas as eras. Gaia

Boas, F. A formação da antropologia americana, 1883-1911: Antropologia. Tradução Rosaura Maria Cime Lima Eichenber. Contraponto / Editora: UFRJ.

Boas, F. Arte Primitiva. Trad. Fabio Ribeiro. Editora Vozes

Bolin, H. Animal Magic: The Mythological Significance of Elks, Boats and Humans in North Swedish Rock Art. In: Journal of Material Culture, 153-76.

Bonfim, F. G. Perspectivas sobre o escrito lacaniano: "a significação do falo". Analytica, 3, 157-182

Bradley, R. Image and audience: rethinking prehistoric art. Oxford: Oxford University Press.

Buco, et al. O Papel das Mulheres Ancestrais nas Pinturas Rupestres do Parque Nacional Serra da Capivara-PI, Brasil. Revista Memória em Rede, Pelotas, 23, $245-273$

Buco, E. Turismo Arqueológico/Archaeological Tourism, Região do Parque Nacional Serra da Capivara/Serra da Capivara National Park region. São Raimundo Nonato: FUMDHAM/Petrobras

Butler, J. Problemas de gênero: feminismo e subversão da identidade. Civilização Brasileira

Castro. Representações sexuais na pré-história, Parque Nacional Serra da Capivara: padrões cenográficos. Trabalho de Conclusão de Curso (Bacharel em Arqueologia). 78f. - Universidade Federal do Vale do São Francisco - UNIVASF.

Childe, G. Para uma recuperação do passado. Trad. Luísa Penafiel.

Clarke, D. Analythical Archaeology. Methuen

Clottes, J. et al. Les Chamanes de la Préhistoire: transe et magie dans le grottes ornées. Paris, Éditions du Seuil

Colling, L., et al. Questões queer para analisar os registros rupestres com cenas que sugerem práticas sexuais na Serra da Capivara. Revista de Arqueologia (Sociedade de Arqueologia Brasileira. IMPRESSO), 32, 24-41, 2019.

Collingwood, R G. Ciência e Filosofia: a ideia de natureza. Editorial Presença, 1986.

Domínguez-Rodrigo, M. El origem de la atracción sexual humana. Akal.

Dubal, L. The art of representation of sexual intercourse. In: Revista Expression, Sexual imagens in prehistoric and tribal art, 14-18.

Eisler, R. O prazer sagrado. Sexo, mito e política do corpo. Trad. Ana Luiza Dantas Borges. 
Epprecht, M. Hungochani: the history of a dissident sexuality in Southern Africa. Montreal: London: McGill-Queen's University Press, 2013.

Etchevarne, C. A ocupação humana do nordeste brasileiro antes da colonização portuguesa. Revista da USP

Fagundes, et al. Paisagem e lugares: considerações sobre a arte rupestre do Sítio Sampaio, Felício dos Santos, Alto Araçuaí, Minas Gerais: uma análise interpretativa. CADERNO DE GEOGRAFIA

Foucault, M. Vigiar e punir: nascimento da prisão. Trad. Raquel Ramalhete

Freud, S. Obras completas volume 11. Totem e tabu, Contribuição à história do movimento psicanalítico e outros textos (1912-1914). São Paulo: Companhia das Letras

Fritz, C., et al. From gesture to myth: artists' techniques on the walls of Chauvet Cave. In: Palethnologie. Archéologie et sciences humaines, n. 7, 2015.

Fuks, et al. Cem anos de Totem e Tabu. Mauad

Garrod, D. A. E. Palaeolithic spear-throwers. Proceedings of the Prehistoric Society

Goldhahn, et al. Engendering North European Rock Art: Bodies and Cosmologies in Stone and Bronze Age Imagery. In: A companion to rock art. New York: Blackwell Publishing Ltd, 2012.

Gomes Filho, et al. Nossos ancestrais praticavam sexo? Diversidade sexual nos registros rupestres do Parque Nacional Serra da Capivara - PI, Brasil. Somanlu - Revista de Estudos Amazônicos18, 1-13.

Gomes Filho, et al. Registros rupestres do Parque Nacional Serra da Capivara-Piauí: breves reflexões sobre a pesquisa antropológica na educação e suas perspectivas interdisciplinares. Ciência e Sustentabilidade - CeS, 4, 39-

Gontijo, et al. Sexualidade e Teoria Queer. Revista de Arqueologia, 30, 51-70

Gopalakrishnan, M. Descoberta Pintura Rupestre Mais Antiga Do Mundo. DW.COM, Arqueologia

Gray. Cave art and the evolution of the human mind. University of Wellington

Guidon, N. Arte Rupestre: Uma síntese do procedimento de pesquisa. Arquivos do Museu de História Natural. UFMG

Guidon, N. A arte pré-histórica de São Raimundo Nonato: síntese de dez anos de pesquisa. Clio, série Arqueológica

Guidon, N. A Fundação Museu Homem Americano e o Parque Nacional Serra da Capivara: um relato sucinto de quatro décadas de pesquisas. In: PESSIS, AnneMarie; GUIDON, Niède e MARTIN, Gabriela. Os Biomas e as Sociedades Humanas na Pré-história da região do Parque Nacional Serra da Capivara. São Paulo: A\&A Comunicação26-44.

Guidon, N. O Pleistoceno Superior e Holoceno Antigo no Parque Nacional Serra da Capivara e seu entorno: as ocupações humanas. In: PESSIS, Anne-Marie; GUIDON, Niède e MARTIN, Gabriela. Os Biomas e as Sociedades Humanas na Pré-história da região do Parque Nacional Serra da Capivara. A\&A Comunicação

Guidon, N. Peintures préhistoriques du Brésil: l'art rupestre du Piauí. Paris: Editions Recherches sur les civilisations

Gunn, et al. Methods, Morelli, rock art, art history: The Morellian method and its potential in rock art research. https://www.researchgate.net/publication/327174874_Methods_Morelli_rock_art_art_history_The_Morellian_method_and_its_potential_in_rock_art_research

Hampson, J G. Rock art regionalism and identity: case studies from Trans-Pecos, Texas and Mpumalanga Province, South Africa. Cambrige: University of Cambridge

Hays-Gilpin, K. Ambiguous images: gender and rock art. Walnut Creek, CA

Helskog, K. Maleness and femaleness in the sky and the underworld - and in between. In: HELSKOG, Knut; OLSEN, Bjornar. Perceiving rock art: social and political perspectives. Oslo: Instituttet for sammenlignende kulturforskning

Hodder, I. Interpretación en Arqueología: Corrientes actuales. Trad. Maria José Aubert e J.A. Editora Crítica

Justamand, M. As rochas de livres prazeres. Revista de História da Biblioteca Nacional.

Justamand, M. A mulher rupestre. Representações do feminino nas cenas rupestres de São Raimundo Nonato - PI. Alexa Cultural

Justamand, M. Comunicar e Educar no território brasileiro: uma relação milenar. : Alexa Cultural

Justamand, M. Corpos em evidência: cenas corpóreas antropomorfas rupestres em São Raimundo Nonato (PI). Revista Cordis. História, Corpo e Saúde, 219245 .

Justamand, M. O Brasil desconhecido, as pinturas rupestres de São Raimundo Nonato têm muito a revelar. SOMANLU: Revista de Estudos Amazônicos, . 0424

Justamand, M. O Brasil desconhecido: as pinturas rupestres de São Raimundo Nonato - Piauí. Achiamé

Justamand, M. Representações das genitálias (falos e vulvas) nas pinturas rupestres do Parque Nacional Serra da Capivara (Piauí, Brasil). ANAIS do XXVI Valcamonica Symposium. Prospects for the prehistoric art research. 50 years since the founding of Centro Camuno. Capo di Ponte. I Edizione multilingua, 147152. 
Justamand, et al. Representações de relações sociais e sexuais entre pessoas do mesmo sexo nas cenas rupestres do Parque Nacional Serra da Capivara-Piauí. Revista Nordestina de História do Brasil, 92-105

Justamand, et al. Representações da sexualidade e dos falos: nas cenas rupestres de São Raimundo Nonato - Piauí muito antes de 1500. Revista Sodebrás, 5356.

Justamand, et al. Representações das genitálias femininas e masculinas nas pinturas rupestres no Parque Nacional Serra da Capivara, PI, Brasil. Revista Anuário de Arqueologia, Rosário, 29-44.

Justamand, et al. Sexual Scenes in Serra da Capivara Rock Art, Brazil. Revista Expression, Sexual imagens in prehistoric and tribal art, n. 15, março/2017, pp. 26-35.

Justamand, et al. Arqueologia, turismo e história e o Parque Nacional Serra da Capivara - PNSC/PI. Revista Interdisciplinar Encontro das Ciências, Icó-Ceará, $01-15$, jan/abr., 2018.

Justamand, et al. Arqueologia da Sexualidade. Representações das genitálias femininas e masculinas nas pinturas rupestres no Parque Nacional Serra da Capivara. Embu das Artes: Alexa Cultural

Justamand, et al. Multiplicidade Sexual nos Registros Rupestres do Parque Nacional Serra da Capivara - PI. Revista de Estudos Amazônicos Somanlu - UFAM, Manaus, 71-92

Justamand, et al.. As principais teorias explicativas acerca da arte rupestre: um estudo de caso. Revista Interdisciplinar Encontro das Ciências, 993-1012, 2020.

Kendirci, et al. The history of male-female sexuality and fertility. 2nd press. Istanbul: Turkish Society of Andrology

Layton, R. Antropologia da Arte. Tradução Abílio Queirós. Edições 70

layton, R. Introdução à Teoria em Antropologia. Edições 70, 2001b.

Le Breton, D. Adeus ao corpo. Antropologia e sociedade. Papirus

Le Goff, J. História e memória. Campinas: Editora da UNICAMP

Ling, et al. Rock art as secondary agent? Society and agency in Bronze Age Bohuslän. In: Norwegian Archaeological Review, 43. 26-43.

Lins. O livro do amor. Vol. 1. Da pré-história à renascença. Best Seller

Lira. Notas sobre a Geografia da Diversidade Sexual. Monografia de conclusão de curso de Licenciatura em Geografia, Universidade Estadual do Piauí. São Raimundo Nonato

Maranca, et al. Populações pré-históricas ceramistas na região da Serra da Capivara. In PESSIS, Anne Marie; MARTIN, Gabriela e GUIDON, Niède. (eds.). Os biomas e as sociedades humanas na pré-história da região do Parque Nacional Serra da Capivara, Brasil, Vol. II-B, FUMDHAM, 481-525.

Martin, G. Amor, Violência e Solidariedade no Testemunho de Arte Rupestre Brasileira. CLIO Revista do Curso de Mestrado em História da Universidade Federal de Pernambuco, 27-. 37 .

Martin, G. Pré-História do nordeste do Brasil. EdUFPE, 1999.

Meltzer, et al. Uma visão da Toca do Boqueirão da Pedra Furada. In: FUMDHAMentos - Revista da Fundação do Museu do Homem Americano, 1, $347-377$.

Mithen, S. The prehistory of the mind. London: Thames and Hudson

Morales JR, R. The Angelim style and northeast Brazilian rock art. In: HUANG, Jennifer K. K.; CULLEY, Elisabeth V (ed.). Making Marks: graduate studies in rock art research at the New Millennium. Tucson: American Rock Art Research Association, 2005. 27-39.

Mykhailova, N. Sex as transition between worlds in deer hunting society (mythology and rock art). Revista Expression. Sexual imagens in prehistoric and tribal art, 58-68.

Nash, G. The subversive male: homosexual and bestial images on European Mesolithic rock art. In: BEVAN, Lynne (ed.). Indecent exposure. Sexuality, society and archaeological record. Glasgow: Cruithne Press

Negreiros. Homoerotismo e educação básica. Monografia de conclusão de curso de Licenciatura em Geografia, Universidade Estadual do Piauí. São Raimundo Nonato

Oliveira, G. F. de. Similaridades e diferenças no complexo estilístico Serra talhada da tradição nordeste de pinturas rupestres no Parque nacional Serra da Capivara-PI: um estudo de caso. Tese de Doutorado em Arqueologia. Laranjeiras: Universidade Federal de Sergipe

Oliveira, et al. Uma história do povoamento do continente americano pelos seres humanos. A odisseia dos primeiros habitantes do Piauí. Embu das Artes: Alexa Cultural e Manaus: EDUA

Oliveira, S. C. de. Figuras emblemáticas na área arqueológica da Serra da Capivara - São Raimundo Nonato - Piauí - Brasil. Dissertação de Mestrado em Arqueologia. Universidade Federal de Pernambuco

Perelló, E. R. Orígenes y significado del arte Paleolítico. Silex Ediciones

Pessis, et al. Imagens da Pré-História. FUMDHAM 
Pessis, et al. Identidades gráficas na arte rupestre: Parque Nacional Serra da Capivara. In: Albuquerque, Marleide Lins e Borges, Síria Emerenciana Nepomuceno (orgs.). Identidades e diversidade cultural: Patrimônio arqueológico e antropológico do Piauí - Brasil e do Alto Ribatejo - Portugal - Coletânea. Teresina: FUNDAC - CEIPHAR/ ITM, 2013, pp.19-33.

Pessis, et al. Arte pré-histórica do Brasil: da técnica ao objeto. In: BARCINSKI, Fabiana (org.). Sobre a arte brasileira. Da pré-história aos anos 1960. Martins Fontes e Edições SESC

Prous, A. Arqueologia Brasileira. Editora Universidade de Brasília

Prous, A. O Brasil antes dos brasileiros. A pré-história do nosso país. Zahar

Queiroz, et al. pampatherium SP, nas pinturas rupestres do Parque Nacional Serra da Capivara - PI, BRASIL. Revista Interdisciplinar Encontro das Ciências, 3,1013-1023

Sansoni, et al. Alpine and Scandinavian rock art in the Bronze Age: a common cultural matrix in a web of continental influences. In: Skoglund, Peter; Ling, Johan; Bertilsson, Ulf (ed.). Picturing the Bronze Age. Oxford: Oxbow Books

Santos Junior, Washington Ramos dos. Localização do Parque Nacional Serra da Capivara. https://www.academia.edu/49082479/Localiza\%C3\%A7\%C3\%A3o_do_Parque_Nacional_Serra_da_Capivara_Piau\%C3\%AD_Brasil.

Searight-Martinet et al. The representation of males and females in the rock art of the Moroccan High Atlas mountains. In: Revista Expression, Male and female, 63-68.

Shanks, M. et al. Social Theory and Archaeology. Albuquerque: University of New Mexico Press

Shanks, M. et al. Re-Constructing Archaeology: Theory and Practice. Londres: Press Syndicate of the University of Cambridge

Silva, Sergio Francisco Serafim Monteiro da; CASTRO, Viviane Maria Cavalcanti de e LIMA, Danúbia Valéria Rodrigues de. Arqueologia do corpo e da sexualidade: possibilidades de estudos sobre morte e gênero na arqueologia brasileira. Clio. Série Arqueológica (UFPE), 26, 49-91

Simoneau, A. Catalogue des sites rupestres du sud marocain. Rabat: Ministère d'État chargé des Affaires Culturelles, 1977.

Soukopova, J. Penis only for gods? Sexual imagery in the earliest central Saharan rock art. In: Revista Expression, Sexual imagens in prehistoric and tribal art, .69-76.

Souza, J. A tolice da inteligência brasileira: ou como o país se deixa manipular pela elite. LeYa

Stearns, P. N. História da Sexualidade. Trad. Renato Marques. Contexto

Tansem, K. et al. The world heritage rock art in Alta. In: Adoranten, 65-84.

Taylor, T. A pré-história do Sexo. Quatro milhões de anos de cultura sexual. Trad. Ana Gibson. Campus

The Arctic University of Norway. Department of Archaeology and Social Anthropology. Gender in Rock Art. 2014. https://www.academia.edu/15391666/Gender_in_Rock_Art.

Ucko, P. Introduction. UCKO, P. (ed) Theory in Archaeology: A World Perspective. Londres, Routledge. Londres, Routledge, p.1-24

Valls. M. P. Similaridades e diferenças indicativas de identidade e evolução cultural no estilo Serra Branca de pinturas rupestres do Parque Nacional Serra da Capivara, Piauí - Brasil. Dissertação de Mestrado em Arqueologia. Recife: Universidade Federal de Pernambuco, 2007.

Vidal, A. Recent discovery of phallic depictions in prehistoric cave in Asia Minor. In: Turkish Journal of Urology, 43, 553-5.

Vidal, A., et al. Engraving gender in Talampaya rock art (Argentina)? In: Revista Expression, Male and female, 82-8.

Vlachopoulos, A. Archaeological fieldwork at Vathy, Astypalaia, with Andreas Vlachopoulos. https://www.youtube.com/watch?v=nsmUI_MbOCs. Acesso 20 fev 2020 .

Vlachopoulos, A. et al. Recent archaeological finds from Vathy, Astypalaia. In: HOPO $\Sigma$ (Horos) Journal - Greek Epigraphic Society, Athens, 22-25, 2014, pp. 375-86.

Wheeler, M. Arqueología del campo. Fondo de Cultura Económica. 